\title{
Constitutive STAT5 activation regulates Paneth and Paneth-like cells to control Clostridium difficile colitis
}

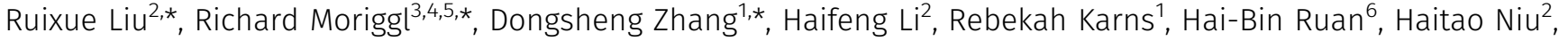 \\ Christopher Mayhew ${ }^{7}$, Carey Watson ${ }^{8}$, Hansraj Bangar ${ }^{9}$, Sang-wook Cha ${ }^{7}$, David Haslam ${ }^{9}$, Tongli Zhang ${ }^{12}$, Shila Gilbert ${ }^{1}$, \\ Na Li², Michael Helmrath ${ }^{8}$, James Wells ${ }^{7,10,11}$, Lee Denson ${ }^{1,13}$, Xiaonan $\operatorname{Han}^{1,2,13}$ (1)
}

Clostridium difficile impairs Paneth cells, driving intestinal inflammation that exaggerates colitis. Besides secreting bactericidal products to restrain $C$. difficile, Paneth cells act as guardians that constitute a niche for intestinal epithelial stem cell (IESC) regeneration. However, how IESCs are sustained to specify Paneth-like cells as their niche remains unclear. Cytokine-JAKSTATs are required for IESC regeneration. We investigated how constitutive STAT5 activation (Ca-pYSTAT5) restricts IESC differentiation towards niche cells to restrain $C$. difficile infection. We generated inducible transgenic mice and organoids to determine the effects of Ca-pYSTAT5-induced IESC lineages on C. difficile colitis. We found that STAT5 absence reduced Paneth cells and predisposed mice to $C$. difficile ileocolitis. In contrast, Ca-pYSTAT5 enhanced Paneth cell lineage tracing and restricted Lgr5 IESC differentiation towards pYSTAT5 ${ }^{+} \mathrm{Lgr5}^{-} \mathrm{CD}_{24} 4^{+} \mathrm{Lyso}^{+}$or $\mathrm{CKit}^{+}$niche cells, which imprinted Lgr $5^{\text {hi }}$ Ki67 $^{+}$IESCs. Mechanistically, pYSTAT5 activated Wnt/ $\beta$-catenin signaling to determine Paneth cell fate. In conclusion, Ca-pYSTAT5 gradients control niche differentiation. Lack of pYSTAT5 reduces the niche cells to sustain IESC regeneration and induces $C$. difficile ileocolitis. STAT5 may be a transcription factor that regulates Paneth cells to maintain niche regeneration.

DOI 10.26508/Isa.201900296 | Received 8 January 2019 | Revised 27 March 2019 | Accepted 27 March 2019 | Published online 4 April 2019

\section{Introduction}

The prevalence of Clostridium difficile infection has increased in patients with inflammatory bowel diseases (IBDs) and has become a major healthcare burden over the past decade (Kaplan, 2015; Rao
\& Higgins, 2016). C. difficile infection is associated with increased disease severity and need for ileostomy or colectomy in patients with IBD (Chen et al, 2017); yet, preventive and therapeutic approaches are extremely limited by a lack of understanding of the essential cell types and key signaling proteins that are usurped in $C$. difficile infection to impair mucosal healing in IBD (Monaghan et al, 2015). Therefore, studying $C$. difficile infection in the context of IBD will directly impact the quest to treat and cure IBD.

C. difficile infection causes a persistent accumulation of enteric toxin A or cytotoxic toxin B and associated pro-inflammatory cytokines detained within intestinal mucosa, likely resulting in intestinal epithelial stem cell (IESC) niche degeneration and suppression of IESC regeneration (Farin et al, 2014; Leslie et al, 2015). The injured IESCS result in impaired intestinal epithelial (IEC) repair and reduced anti-microbial peptide production, which in turn drives persistent infection and mucosal inflammation progression to ileitis and/or colitis (Monaghan et al, 2015). STAT5-dependent JAK2 signaling is required for anti-inflammatory cytokine production and IEC repair, and mutations or single nucleotide polymorphisms in JAK2-STAT5 increase susceptibility to colitis and ileal Crohn's disease (Gilbert et al, 2012a; Huang et al, 2015; Chuang et al, 2016). C. difficile toxin has been implicated in suppression of the Wnt and JAK2-STAT5 pathways to impair IECS (Nam et al, 2012; Chen et al, 2018), but mechanistic studies are lacking.

Niche cells are located at the crypt bases that directly surround IESCS and provide a microenvironment that maintains Lgr5 IESC self-renewal (Sato et al, 2011; Rothenberg et al, 2012; Watt \& Huck, 2013; Sasaki et al, 2016). IESCs and progenitor cells along with their regulatory secretory niche cells are thought to regulate crypt immune specialization to restrain infection and control the IEC healing response to inflammation (Barker, 2014; Mowat \& Agace, 2014). In addition to secreting anti-microbial peptides for gut innate

\footnotetext{
${ }^{1}$ Division of Gastroenterology, Hepatology and Nutrition, Cincinnati Children's Hospital Medical Center (CCHMC), Cincinnati, OH, USA ${ }^{2}$ Key Laboratory of Human Disease Comparative Medicine, the Ministry of Health, Institute of Laboratory Animal Sciences, Chinese Academy Institute of Medical Sciences and Peking Union Medical College, Beijing, P.R. China ${ }^{3}$ Ludwig Boltzmann Institute for Cancer Research, Vienna, Austria ${ }^{4}$ Institute of Animal Breeding and Genetics, University of Veterinary Medicine, Vienna, Austria ${ }^{5}$ Medical University of Vienna, Vienna, Austria ${ }^{6}$ Department of Integrative Biology and Physiology, University of Minnesota Medical School, Minneapolis, MI, USA ${ }^{7}$ Division of Developmental Biology, CCHMC, Cincinnati, OH, USA ${ }^{8}$ Division of Pediatric Surgery, CCHMC, Cincinnati, OH, USA ${ }^{9}$ Division of Infectious Diseases, CCHMC, Cincinnati, OH, USA ${ }^{10}$ Division of Endocrinology, CCHMC, Cincinnati, OH, USA ${ }^{11}$ Center for Stem Cell and Organoid Medicine, CCHMC, Cincinnati, OH, USA ${ }^{12}$ Department of Pharmacology \& Systems Physiology, University of Cincinnati College of Medicine, OH, USA ${ }^{13}$ Department of Pediatrics, University of Cincinnati College of Medicine, $\mathrm{OH}, \mathrm{USA}$
} 
immunity to mediate the interaction with microbiota, Paneth cells act as defined niche cells of IESCs. In contrast, dysfunctional Paneth cells can serve as the site of origin for intestinal inflammation (Adolph et al, 2013). These reports indicate that specific Paneth cell phenotypes occur in intestinal diseases, such as colitis or enteric infection, and these phenotypes indicate either host prevention of intestinal injuries or exaggerated mucosal inflammation (VanDussen et al, 2014). Perhaps more intriguing, the misallocation of Paneth cells can be induced by various mucosal injuries or wound-healing factors (Nakanishi et al, 2016), suggesting that the sublineages of Paneth cells or Paneth-like cells may be differentiated to maintain the feed-forward loop of IESC regeneration (Schewe et al, 2016).

The biological efficacy of cytokines is often dependent on their ability to generate a sustained, rather than transient, stimulation of their target cells (Stark \& Darnell, 2012). Persistent phosphorylated STAT5 (PYSTAT5) results in the maturation of mammary gland that maintains secretion (Xu et al, 2009). In our previous work (Gilbert et al, 2015), we found that Stat5 variants (STAT5a-ER) could be activated by different doses of tamoxifen (Tam) or by STAT5-activating cytokines or growth hormones (granulocyte-macrophage colony-stimulating factor [GM-CSF], c-Kit ligands, Leptin, Prolactin [Prl], and Growth Hormone $[\mathrm{GH}]$ ), to represent physiological activation of cellular STAT5 (Grebien et al, 2008). In contrast, inducible constitutively active Stat5 (icS5) variants are "superactivatable" and can mimic persistent tyrosine kinase signaling independent of cytokine stimulation (Moriggl et al, 2005). Importantly, icS5 dosage can be controlled by chemical induction (Grebien et al, 2008; Gilbert et al, 2015). Low to intermediate levels of STAT5 activity confer self-renewal capacity to IESCS and hematopoietic stem cells (Wierenga et al, 2008; Gilbert et al, 2015), while higher or sustained STAT5 activation leads to progressive lineage differentiation and functional maturation, as in the case of mammary cell secretion (Yoo et al, 2015). Therefore, in vivo and in vitro icS5 are important tools for studying the effects of niche cytokine signaling upon IESC-dependent regeneration repair, as little is known about the mechanism of cytokine signaling that enables IESCS to restrict cell fates for specializing crypt immunity, such as architecture, anti-microbial secretion, and crypt cell hierarchy. Here, by differentiating human inducible pluripotent stem cells (iPSCs) or murine adult IESCS and utilizing compound mutant mice (Gilbert et al, 2012a, 2015), we defined a population of IESCS by which constitutive STAT5 activation (Ca-pYSTAT5) regenerated the niche, and unveiled the effects of defective JAK2-STAT5 signaling upon IESC niche cells, leading to susceptibility to enteric infection and ileocolitis.

\section{Results}

\section{Lack of pYSTAT5 predisposes mice to $C$. difficile infection-induced ileitis and colitis}

C. difficile causes diarrhea and pseudomembranous colitis via toxin A and cytokine-induced IEC integrity disruption (Johal et al, 2004), and potent toxin B cytotoxicity (Giesemann et al, 2008). Interestingly, apart from toxin-induced cytotoxicity, C. difficile infection leads to the activation of a cascade of mucosal proinflammatory cytokines, including IFN $\gamma$, TNF $\alpha$, and IL $1 \beta$, that result in recurrent colitis or ileitis (Abt et al, 2016). Some studies found that Paneth cell Defensins ( $\alpha$-Defensins) inhibited toxin B possibly through promoting the unfolding of toxin protein, rendering it susceptible to proteolysis. This observation suggests a direct bactericidal role of Paneth cells in controlling hypervirulent $C$. difficile (Giesemann et al, 2008; Hing et al, 2013). Importantly, Paneth cells maintain host-microbiota homeostasis (Zhang et al, 2015a), as genetic defects in Paneth cells cause intestinal dysbiosis and increase susceptibility to both IBD (Wehkamp et al, 2007) and C. difficile ileitis or colitis (ileocolitis) (Giesemann et al, 2008). Together, these reports suggest a crucial role for host factors, such as IESC regeneration, Paneth cell differentiation, or crypt immune specification in the $C$. difficile-associated IBD severity.

Generally, C. difficile infection leads to scant exudate, surface colonization by $C$. difficile, submucosal neutrophil infiltrate, submucosal edema, IEC necrosis, goblet cell depletion, and transmural necrosis in the cecum and colon (Hing et al, 2013). We observed that C. difficile-infected IEC Stat5-deficient mice (VilCreER;Stat $5^{\mathrm{f} / \mathrm{f}}$; STAT5 $^{\Delta \mathrm{EEC}-l^{-}}$) showed more severe cecal inflammation and colitis, characterized by more colonic goblet cell depletion, more severe pseudomembranous colitis and crypt necrosis, and worse mucosal coagulative necrosis than these lesions in C. difficile-infected controls $\left(\mathrm{STAT5}^{+/+}\right)$. In contrast, inducible activation of STAT5 in IECS (VilCreER;icS5; STAT5 ${ }^{\Delta \mathrm{EC}+++}$ ) alleviated cecal mucosal inflammation (Fig 1 A and B). Additionally, significant weight loss (Fig S1A) and increased mortality was found in Stat5-deficient mice (Fig 1C). Importantly, we found that compared with controls (C. difficiletreated Lgr5CreER mice), C. difficile-infected Stat5-deficient mice (Lgr5CreER;VilCreER;Stat5) displayed virtually no Lgr5-GFP cell proliferation as measured by $\mathrm{LgrS}^{+}$and $\mathrm{Ki}^{\mathrm{C}} \mathrm{T}^{+}$IECS at crypt bases whereas activated STAT5 (Lgr5CreER;VilCreER;iCS5) induced remarkable Lgr5 IESC proliferation indicated by Lgr5 ${ }^{+}$and Ki67 ${ }^{+}$crypt IECs during C. difficile infection (Fig 1D and Fig S1B). Intriguingly, we found that STAT5-deficient mice are more susceptible to $C$. difficile-induced terminal ileitis (Fig 1E). C. difficile-induced ileitis in Stat5-deficient mice was characterized by ileal Paneth cell depletion, pseudomembrane formation, crypt abscess, and ileitis, while $C$. difficile-infected control mice did not show any enteritis (Fig 1F). In contrast, the activation of STAT5 in IECS robustly increased Paneth cell expansion (Fig $1 E$ and F). These data indicate that the lack of pYSTAT5 induces C. difficile ileocolitis. Active STAT5 counteracts $C$. difficile-induced IEC or IESC injuries, possibly through promotion of niche-dependent Lgr5 IESC regeneration. Dextran sodium sulfate (DSS) induces colitis that may lead to colonic IEC damage and IESC regeneration, but it is unclear whether these regenerated IESCS are dependent on niche cells (Metcalfe et al, 2014). By exposing mice to three cycles of DSS, we created a chronic colitis in mice, in which chronic inflammation led to a large amount of regenerated colonic crypts (Wirtz et al, 2017). Interestingly, PYSTAT5 was found to be highly activated in those nascent colonic crypts, suggesting the protective role of PYSTAT5 in colonic IESC regeneration (Fig S1C). We next ask whether pYSTAT5 protects IESC regeneration by enhancing intestinal Paneth cell or colonic niche differentiation. 
A
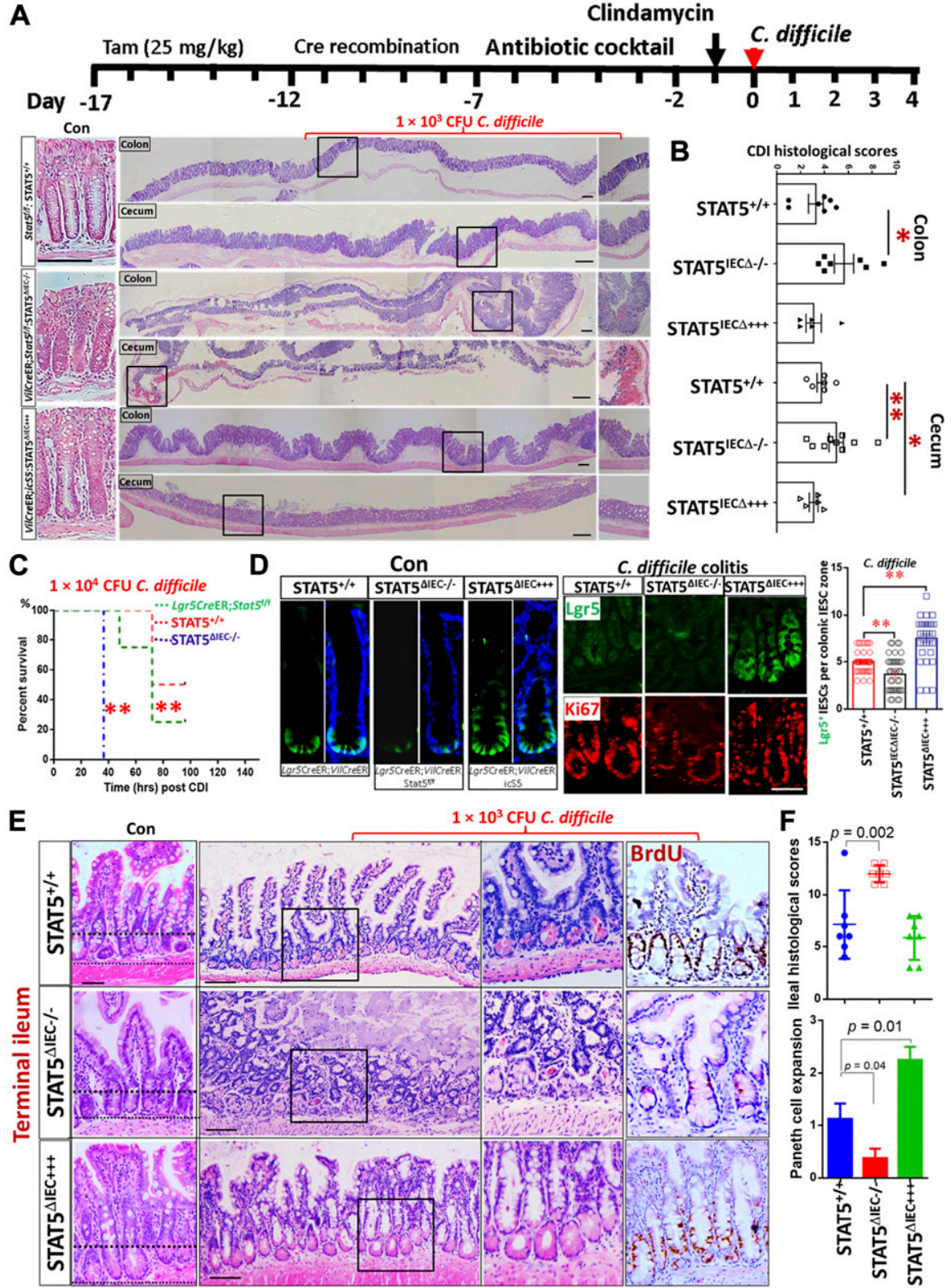

.

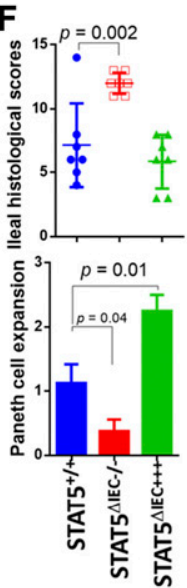

Figure 1. Lack of pYSTAT5 predisposes mice to C. difficile ileocolitis.

(A, B) STAT5 ${ }^{+/+}$, STAT5 $^{\Delta \mathrm{ECC}-l_{-}}$, and STAT5 ${ }^{\Delta \mathrm{EC}+++}$ mice were inoculated with $1 \times 10^{3} \mathrm{CFU} C$. difficile for $4 \mathrm{~d}$. Histopathology of colonic and cecal inflammation was scored. Results are expressed as mean $\pm S E M, n \geq 5$ mice per group ${ }^{* *} P<0.01$ versus STAT5 ${ }^{+/+}{ }^{*} P<0.05$ versus $\mathrm{STAT}^{+/+}$. (C) Mice were inoculated with C. difficile at $1 \times$ $10^{4}$ CFU per mouse. Inducible depletion of STAT5 in IECS or IESCS significantly reduced survival following $C$. difficile infection. Survival was analyzed with Kaplan-Meier estimates, $\mathrm{n}=7$ mice per group, ${ }^{* *} P<0.01$ versus STAT5 ${ }^{+/+}$mice. (D) Lgr5CreER;VilCreER;icS5 mice were treated with C. difficile. Lgr5 ${ }^{+}$IESCs were counted in 200 crypts in colonic mucosa, $\mathrm{n} \geq 3$ mice per group. Results are expressed as mean \pm SEM, ${ }^{*} P<0.05$ versus Lgr5CreER mice. Representative images of $\mathrm{Lgr}^{+}$IESCs in control (Con) and C. difficle colitis are shown. $(\mathbf{E}, \mathbf{F})$ The severity of ileitis was scored as neutrophil infiltration, submucosal edema, IEC necrosis, and Paneth cell or goblet cell depletion. Paneth cell depletion or expansion was semi-quantitated in C. difficile-infected

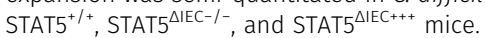

Histological scores show that STAT5 ${ }^{\Delta \mathrm{EC}-1-}$ mice display worse ileal inflammation than STAT5 ${ }^{+/+}$mice, while STAT5 ${ }^{\Delta \mathrm{EC}+++}$ mice exhibit IEC protection and more regenerated $\mathrm{BrdU}^{+} \mathrm{IECS}$. Results are expressed as mean $\pm \mathrm{SEM},{ }^{*} P<0.05$ versus STAT5 ${ }^{\Delta \mathrm{EC}-1-}$ mice, $\mathrm{n} \geq 5$ mice per group. All results are expressed as mean $\pm \mathrm{SEM}$, and $t$ tests and ANOVA were used to compare the significance of a difference.

\section{Alteration of Paneth cell maturation and migration in IEC STAT5 mutant mice}

Paneth cells produce the EGF, Wnt3, and Notch ligand Dll4 that are essential for Lgrh" IESCs to establish a "3D" minigut, demonstrating that Paneth cells constitute the Lgr5 ${ }^{\text {hi }}$ IESC niche (Sato et al, 2011). Previously, we reported that IESCS require STAT5 signaling to regenerate damaged IECS (Gilbert et al, 2015). However, it is largely unknown how STAT5 controls IESC regeneration. Using inducible VilCreER that can control levels of STAT5 expression in IECS in a Tam-inducible manner, we found that induced deletion of Stat5 in IECs significantly reduced the numbers of Lysozyme (Lyso) ${ }^{+}$Paneth cells and the size of the niche (Figs 2A and S2A). However, Paneth cells are not completely disappearing, suggesting other compensatory pathway activation or inhibition induced by STAT5 depletion (Heuberger et al, 2014). In contrast, STAT5 activation in IECs induced by $5 \mathrm{~d}$ of Tam treatment increased Lyso production (Fig 2B), numbers of Paneth cells (Fig 2A and C), and Lyso, Muc2, Defensin1, and Defensin10 expression (Fig 2D). Interestingly, the activation of STAT5 led to a significant migration of Paneth cell from crypt bases towards villi, characterized by ectopic Lyso ${ }^{+}$cells above the crypt-villus junctions, more granules in the cytoplasm, and a larger niche volume than controls (Fig $2 \mathrm{~A}$ and $\mathrm{E}$ ). Of note, there are significantly increased numbers of Lyso $^{+} A B^{+}$crypt IECS in the $\mathrm{STAT}^{\mathrm{\Delta IEC+++}}$ compared with $\mathrm{STAT5}^{+/+}$mice but they are not on the villi (Fig S2B), suggesting that the activated STAT5 affect intermediate secretory progenitors towards crypt cell differentiation or dedifferentiation (Nusse et al, 2018; Schmitt et al, 2018). Perhaps 
A
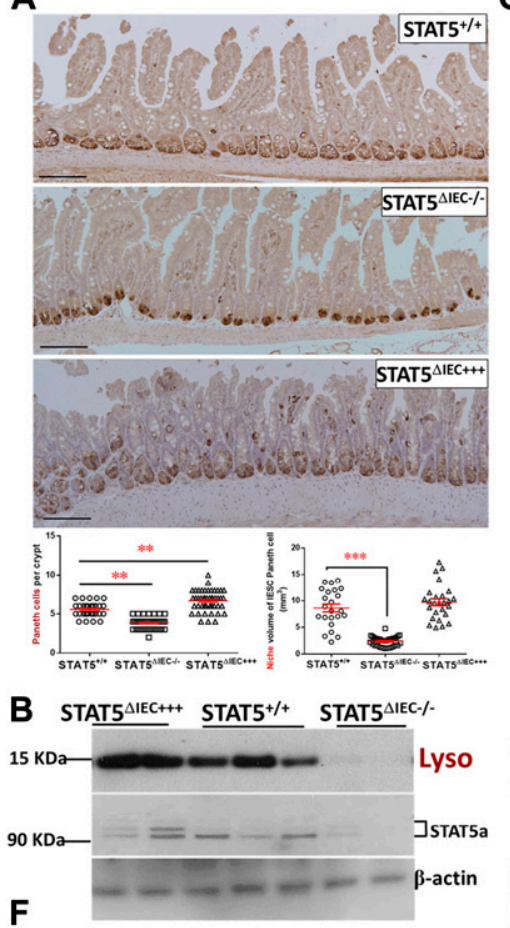

$\mathbf{F}$

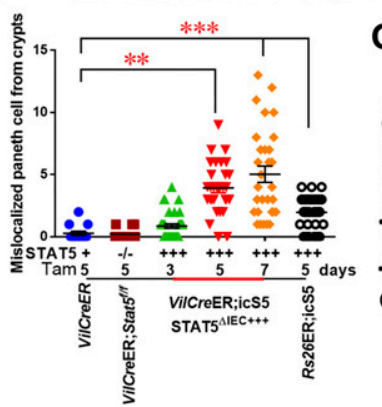

C
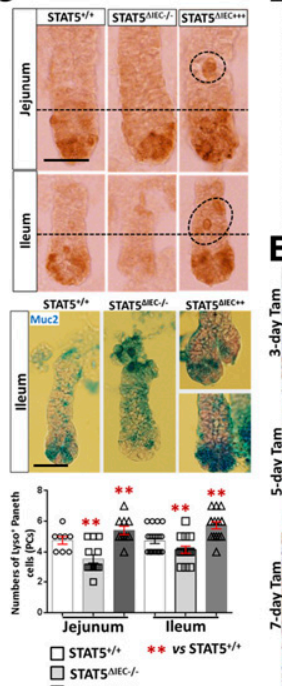
$\square$ STATS AIECH.
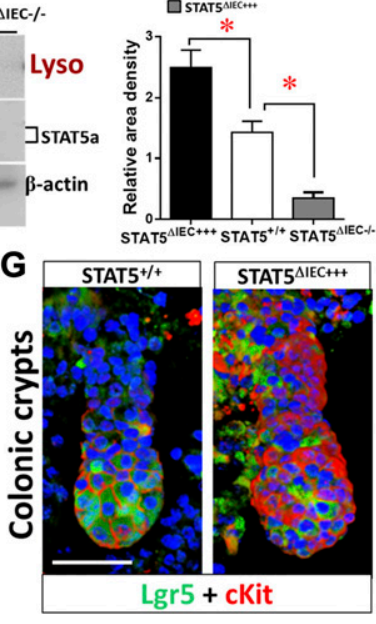

D
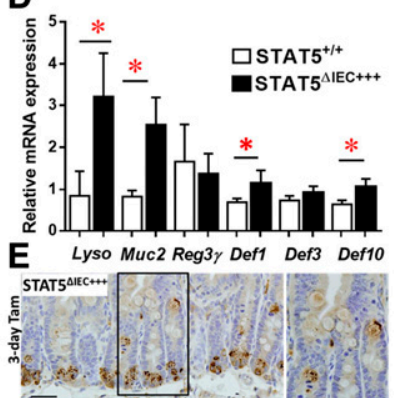

sT:
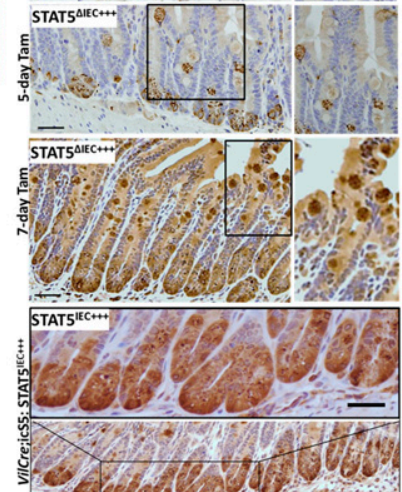

H

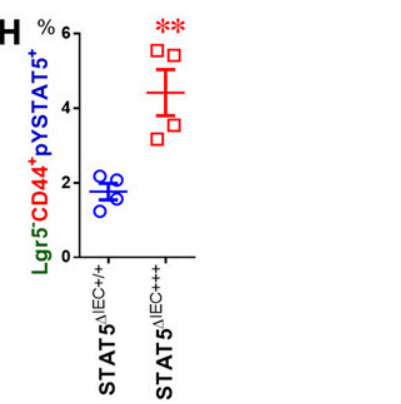

Figure 2. STAT5 signaling regulates Paneth cells in a dose-dependent manner.

Stat5 or icS5 floxed mice were crossed with VilCreER. VilCreER;Stat5 or icS5 mice, and then treated with Tam for 3, 5 , or $7 \mathrm{~d}$ followed by 5-d Cre recombination. (A) Paneth cells were determined with Lyso immunohistochemistry $(\mathrm{IH})$ and $\mathrm{IF}$ staining. Average numbers of Lyso ${ }^{+}$Paneth cells were counted in 200 crypts, and the size of Paneth niche was measured as volume with confocal microscopy (Fig S2A). (B) Intestinal crypts were isolated, total proteins were extracted, and immunoblotting was performed to determine Lyso and STAT5a protein expression. Densitometry was used to determine the expression of Lyso relative to $\beta$-actin. Results are expressed as mean \pm SEM, $n \geq 5$ mice per group. (c) Jejunal and ileal crypts were isolated and stained with Lyso IH and AB. Lyso ${ }^{+}$ crypt cells were counted in 200 isolated crypts. (D) Realtime PCR was performed to determine anti-microbial peptide expression in $\mathrm{STAT5}^{+/+}$and STAT5 ${ }^{\Delta \mathrm{EC}+++}$ mice. (E) Ectopic Paneth cells were counted as the number of migrated Lyso ${ }^{+}$IECS from crypt bases to villi in 3,5, and $7 \mathrm{~d}$ Tam-treated VilCreER or $5 \mathrm{~d}$ Tam-treated Rs26CreER or VilCre;icS5 mice. Scale $=200 \mu \mathrm{m}$. (F) Over 200 villi and crypts were counted. Results are expressed as mean \pm SEM, $\mathrm{n} \geq 5$ mice per group. (G) Colonic crypts were double-stained with anti-Lgr5 (green) and anti-cKit (red), and 3D images were captured with confocal microscopy, $\mathrm{n}>3$ mice each group. (H) Colonic crypts were disassociated with TrypLE into IECs. Lgr5-GFP' and ${ }^{+}$IECS were then separated by gating with FACS. PE-Cy7-conjugated PYSTAT5 and APC-conjugated CD44 staining were used to quantitate pYSTAT5 ${ }^{+} \mathrm{Lgr} 5^{-} \mathrm{CD} 44^{+}$ colonic crypt IECS, $n=4$ mice per group, ${ }^{* \star} p<0.01$ versus $\mathrm{STAT5}^{+/+}$. All results are expressed as mean $\pm \mathrm{SEM}$, and $t$ tests and ANOVA were used to compare the significance of a difference. more intriguing, the numbers of ectopic Paneth cells were correlated with the duration of Tam induction (Fig $2 \mathrm{E}$ and $\mathrm{F}$ ), and persistent PYSTAT5 in IECS driven by VilCre (Fig S2C) led to broad Paneth cell expansion, metaplasia, crypt fission (Fig 2E), and the appearance of dysplastic crypts (Fig S2D). These data suggest that STAT5 is a key transcription factor that regulates Paneth cell differentiation.

Although Paneth cells are a defined niche of intestinal IESCS, they are not found in colon at homeostasis. There is a distinguished population of secretory IECS, they reside at the colonic crypt base to serve as colonic IESC niche, which can be labeled by CKit, Reg4, Muc2, and Alcian blue (AB), and this process requires Notch inhibition (Rothenberg et al, 2012; Sasaki et al, 2016). These secretory cells are currently referred to as colonic deep crypt secretory cells (DCSs) (Sasaki et al, 2016). We found that Ca-pYSTAT5 increased cKit ${ }^{+}$ crypt IECs and phospho-cKit (pcKit) in colonic crypt IECs (Figs $2 \mathrm{G}$ and S2E). Importantly, our FACS analysis showed that compared with controls, Ca-pYSTAT5 led to a population of colonic crypt cells: pYSTAT5 ${ }^{+}$Lgr5 ${ }^{-} \mathrm{CD}_{4} 4^{+}$cells (Fig $2 \mathrm{H}$ ), which could have a direct role in protecting colonic IESCs from pro-inflammatory or C. difficile toxins.
Taken together, pYSTAT5 protects the host from C. difficle toxin injury, possibly by acting on intestinal Paneth cells and/or colonic DCS cells.

\section{Constitutive STAT5 signaling enhances lineage tracing at crypt bases}

STAT5-dependent regeneration may be due to autonomous regulation of IESC progeny fates or secondary to other events, such as apoptosis or survival following injuries (Gilbert et al, 2015). To determine the primary effects of STAT5 on IESCS, we performed a lineage-tracing study. Lgr5CreER mice were first crossed with Rosa26-stop-tdTomato mice (RstdTomato) to generate a mouse line (hereafter called Lgr5-tdTomato). The Lgr5-tdTomato, a compound mutant model, permits tracing of Lgr5 ${ }^{+}$IESC progeny within intestines and robust labeling of daughter cells for visualization (Barker et al, 2007) (Fig 3A). Lgr5-tdTomato mice were then crossed with icS5 floxed mice (thereafter called Lgr5tdTomato;icS5). These compound mice allowed us to trace the effects of gain or loss of function of STAT5 in Lgr5 IESCS upon their 


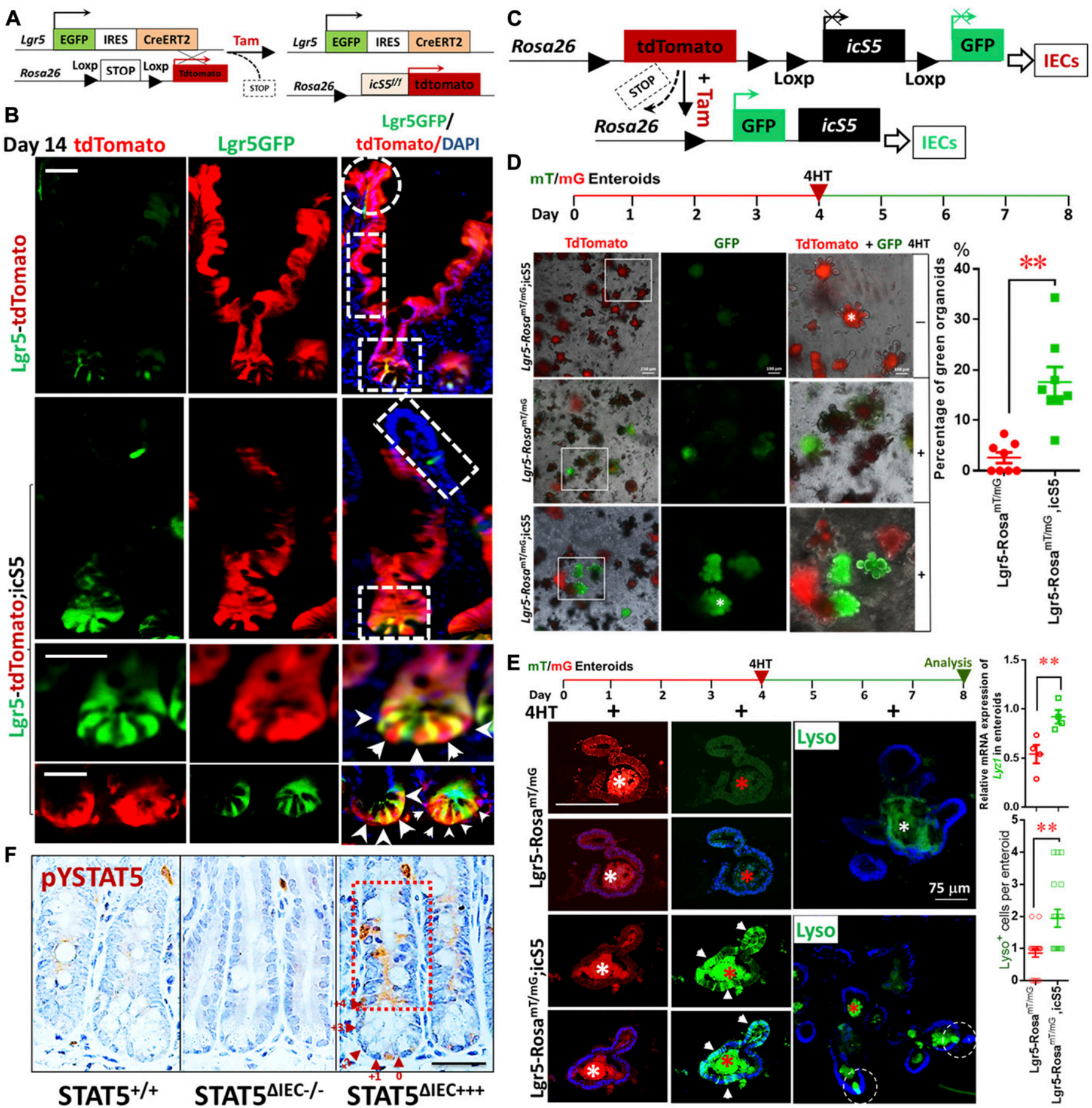

Figure 3. pYSTAT5 enhances lineage tracing of crypt secretory cells.

(A) Lgr5-tdTomato mice were generated for IEC lineage analysis with a single dose of Tam. (B) One dose of Tam (25 mg/ kg) was given to Lgr5-RstdTomato;icS5 mice $14 \mathrm{~d}$ later. Intestinal lineage tracing shows that tdTomato-labeled Lgr5 ${ }^{+}$progeny (red/green) are shown in the squares at crypt bases and Lgr5 and Paneth cells (red) are marked by arrowheads and counted (Fig S3C). tdTomato-labeled Lgr5(red) cells are shown in the rectangles on the villi, and the repopulated IECs are shown in the circle on the tip of the villus in the red ribbons. 200 crypts were counted, three mice per group. (C) $L g r 5 C r e E R$ mice were crossed with Rosa ${ }^{m T / m G}$ mice to generate Lgr5-Rosa ${ }^{m T / m G} ;$ icS5 mice. (D) Enteroids from Lgr5-Rosa $a^{m T / m G} ;$;icS5 mice were differentiated, and then constitutive icS5 was induced with $4 \mathrm{HT}$ (200 nM) for 4 d. Enteroids prior to or after $4 \mathrm{HT}$ induction were imaged. The switch percentage from red to green enteroids was determined after $4 \mathrm{HT}$ induction in three experiments.

(E) Enteroids prior to or after $4 \mathrm{HT}$ induction were fixed and sectioned. Images were collected. Arrowheads show green ribbon along villi. Lyso ${ }^{+}$Paneth cell-like cells were immunostained as the circles (green) and were quantitated. *Autofluorescence. Total RNA was extracted from the enteroids, and the expression of Lyz1 was quantitated by real-time PCR. Results are expressed as mean \pm SEM, $n=4$ or 5 wells of enteroids per group. ${ }^{*} P<0.01$ versus Lgr5-RosamT/mG. (F) Ileal sections were stained with pYSTAT5 IH (brown). $n \geq 5$ mice per group, Scale $=200 \mu \mathrm{m}$. All results are expressed as mean \pm SEM, and $t$ tests and ANOVA were used to compare the significance of a difference. 
progeny following a single dose of Tam induction $(25 \mathrm{mg} / \mathrm{kg}$, Figs $3 \mathrm{~A}$ and S3A). After 1, 7, 15, 30, and $60 \mathrm{~d}$ following a single dose of Tam, lineage tracing demonstrated that the parallel red ribbons that contained all intestinal or colonic IEC types emanated from the crypt bottoms and ran up the side of adjacent villi in Lgr5tdTomato mice (see squares at crypt and rectangles on villus, Figs 3B, S3B, and C). In contrast, the activated STAT5 in IESCs led to the red ribbons that remained at the intestinal and colonic crypt bases even after 15-d lineage tracing, showing significantly greater numbers of tdtomato-labelled Paneth cells and colonic Paneth-like cells at the crypt bases compared with controls (see squares at crypts, Figs 3B, S3B, and C); these stained IEC lineages climbed significantly slower along the intestinal villi compared to those in their littermate controls 15, 30 (data not shown), or $60 \mathrm{~d}$ later (see rectangles on villi, Figs 3B and S3C). Lgr5CreER mice were then crossed with Rosa26-stop-LacZ mice (LacZ) to generate a mouse line (thereafter called Lgr5-LacZ), which can be used to demonstrate the regulatory genes of IESC progeny fates (Fig S4A) (Barker \& Clevers, 2010). Interestingly, following a single dose of Tam, Lgr5-LacZ;Stat5 mice displayed a reduced LacZ staining and decreased tracing presence at the intestinal or colonic bases (Fig S4B-D), indicating that STAT5 is an intrinsic signaling that is required for IESC self-renewal.

Rosa $^{m T / m G}$ mice present a conditional fluorescent reporter mouse model (Rosa ${ }^{m T / m G}$ ), in which the fluorescent proteinencoding transgenes were rearranged following Tam-mediated cre-recombinase and transgene expression of red-tdTomato fluorescent protein was converted to the expression of greenGFP (Fig 3C) (Muzumdar et al, 2007). By crossing Rosa ${ }^{m T / m G}$ mice with Lgr5CreER-icS5 mice (hereafter called Lgr5-Rosa ${ }^{m T / m G}$;icS5), we generated a line of mice with Tam-inducible constitutively active STAT5 (Fig 3C). Subsequently, we differentiated 14-d enteroids and maintained part of these in culture medium with 200 mM 4-hydroxytamoxifen (4HT) for 4 d (Gilbert et al, 2015). Concomitant with in vivo lineage tracing, our in vitro lineage study showed that after $4 \mathrm{HT}$-induction, red-tdTomato fluorescence in Lgr5-Rosa ${ }^{m T / m G}$;icS5 enteroid was largely absent, while green-GFP cells, a large portion of which were stained as Lyso ${ }^{+}$ Paneth cells or Sox9 $9^{+}$cells, were highly and rapidly enriched compared to $4 \mathrm{HT}$-treated Lgr5-Rosa $\mathrm{mT} / \mathrm{mG}$ controls. These enteroids also expressed the higher levels of Lyz1 or Sox9 than controls (Figs 3D, E, S4E, and F). Taken together, these data indicate that STAT5 signaling regulates IESC progeny differentiation and more specifically that PYSTAT5 in IESCS enhances IESC lineage tracing to increase crypt Paneth cell differentiation, while loss of Stat5 leads to reduced IESC self-renewal and stemness. Interestingly, our compound mouse models showed that constitutively activated STAT5 in IECS increased PYSTAT5 in the transitamplifying (TA) IECS and crypt base IECS (see rectangle and arrowheads, Fig 3F), some of which were co-localized with nucleic Ki67 in TA IECs (see circles in TA zone, Fig S4G). This observation suggests that these pYSTAT5 ${ }^{+}$Lgr $5^{\text {low }} \mathrm{Ki} 67^{+}$IECS in the TA zone may be a progenitor population determined by cytokines, hormones, or growth factors that steer pYSTAT5 signaling from Lgr5 IESCS (Basak et al, 2014). Thus, we next determined the functions of these pYSTAT5 ${ }^{+}$Lgr5 $^{\text {low }}{\text { Ki } 67^{+}}$IECS and the fate of their progeny as induced by PYSTAT5.

\section{pYSTAT5 restricts Lgr5 $^{\text {low }} \mathrm{Ki}^{+} 7^{+}$IESCs to give rise to pYSTAT5 $^{+}$Lgr5 $^{-}$ CD24 ${ }^{+}$Paneth cells}

Clevers' group reported that the $\mathrm{Lgr} 5^{\text {low }} \mathrm{Ki} 67^{+}$IESC population above Paneth cells expresses high levels of Stat5a gene in association with significantly increased gene signatures of secretory lineages after induced activation (Basak et al, 2014). These secretory cells induced from Lgr5 ${ }^{\text {low }} \mathrm{Ki} 7^{+}$IESCS reside at the crypt base to serve as an IESC niche, which can be labeled by Lyso, C-Kit, CD24, CD44, and AB staining (Rothenberg et al, 2012; Sasaki et al, 2016). These reports suggest that Stat5 may be required for $\mathrm{Lgr5}^{\mathrm{low}} \mathrm{Ki} 67^{+}$IESCS to differentiate into Paneth cells at crypt bases, providing the most critical regional immunity against microbial invasion and inflammatory insults (Mowat \& Agace, 2014). After 5-d Tam induction, we found that activated STAT5 significantly increased PYSTAT5 ${ }^{+}$ Lgr $5^{-} \mathrm{CD} 24^{+}$intestinal crypt IECS detected in gate P1 by FACS tracing experiments (Figs 4 A and S5A). On the contrary, the depletion of Stat5 led to a pronounced reduction of $\mathrm{Lgr}^{-} \mathrm{CD} 24^{+} \mathrm{IECs}$ detected in gate P2 (Fig 4A). These results are consistent with our above observations which showed that activated STAT5 increased Paneth cells at the crypt bases (Fig 2A). Intriguingly, using the dissociated IECS from directly isolated crypts, the FACS analysis revealed that the activated STAT5 increased $\mathrm{Lgr5}^{\mathrm{hi}}: \mathrm{CD}_{2} 4^{+}$cell doublets (Figs 4B and $\mathrm{S} 5 \mathrm{~B}$ ). This result is consistent with our confocal microscopy results, showing the increased numbers of Lgr5-GFP and CD24 COimmunostaining doublet in STAT5 ${ }^{\Delta \mathrm{IEC+++}}$ mice (see circles, Fig 4C). Thus, STAT5 activation increases IESC niche cells.

Single-sorted $\mathrm{Lgr}^{\mathrm{hi}}$ crypt base columnar cells (CBCs) rarely generate miniguts, whereas CBC:Paneth cell doublets robustly grow into a minigut (Sato et al, 2011). Thus, we grew enteroids containing Lgr5 $^{\text {hi }}$ CBCS and niche cells from Lgr5CreER;VilCreER,icS5 mice and performed an injury study with irradiation to investigate the effects of STAT5 activation upon the regenerative capacity of Lgr5-GFP ${ }^{+}$ enteroids (Fig 4D). The activated STAT5 increased Lgr5 $^{+}$enteroid regeneration as characterized by significantly more remaining Lgr5 $\mathrm{GFP}^{+}$buds in the enteroids compared with irradiation-treated controls (Lgr5CreER;VilCreER;icS5 versus Lgr5CreER;VilCreER mice, Figs 4D and S5C), higher proliferation of $\mathrm{Lgr}^{\mathrm{hi}} \mathrm{Ki}^{\mathrm{K}} \mathrm{7}^{+} \mathrm{pYSTAT5}^{+} \mathrm{IESCS}$, and non-significant change of Lgr5 $^{\text {low }} \mathrm{Ki} 7^{+}$pYSTAT5 ${ }^{+}$IESCS under basal conditions (Fig 4E and F). Interestingly, irradiation reduced

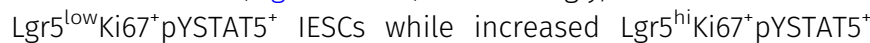
IESCs in the control enteroids compared with basal conditions. In contrast, the activated STAT5 induced more Lgr5 $^{\text {low }}$ Ki67 $^{+}$PYSTAT5 $^{+}$ IESC regeneration after irradiation compared to irradiation-treated control enteroids (Fig 4F). Consistently, the activated STAT5 increased the resistance of colonoids to the radiation-induced injury, as shown by more Lgr5-GFP buds in STAT5-activated colonoids compared with the relatively less buds in controls $6 \mathrm{~d}$ postradiation (Fig 4G). Stem cell factor (SCF), a cKit ligand, is known to act as an agonist of JAK2-STAT5 signaling (Nakai et al, 2008). SCF is highly expressed in the subepithelial stromal cells during gut injury (Schmitt et al, 2018). These secreted SCF could be the source to induce PYSTAT5 in CKit $^{+}$DCSs. Consistently, we found that SCF significantly promotes colonoid proliferation at $20 \mathrm{ng} / \mathrm{ml}$ (Fig S5D and E). Therefore, Ca-pYSTAT5 stimulates colonoid proliferation possibly by increasing SCF-activated cKit colonic IECS. Together, these data suggest that the STAT5 activation protects IESC 
A

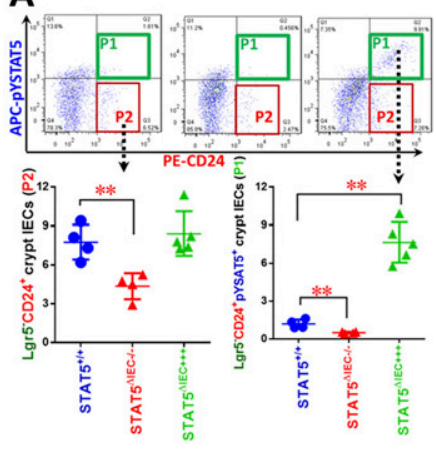

\section{Enteroids}

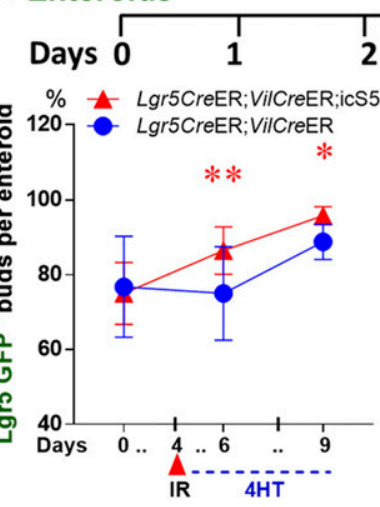

B

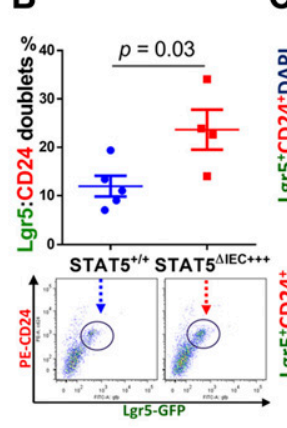

C

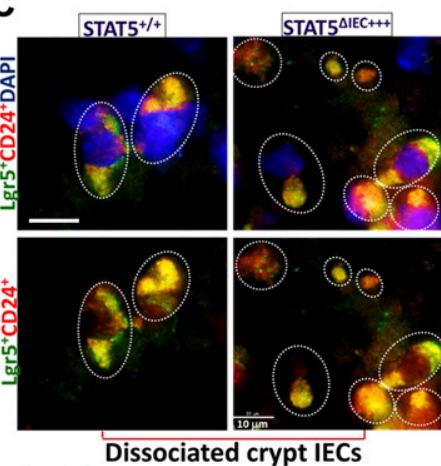

Dissociated crypt IECs R (4 Gy) + 4HT
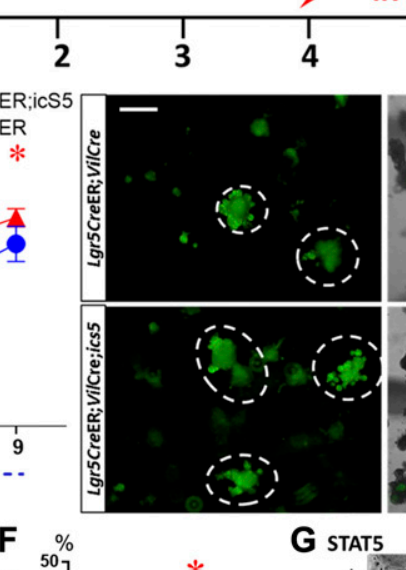

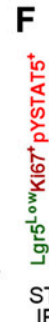

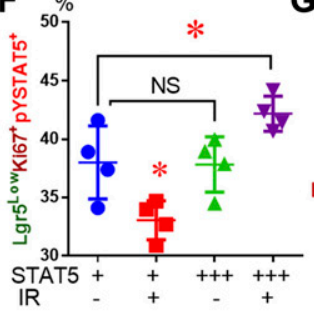

6
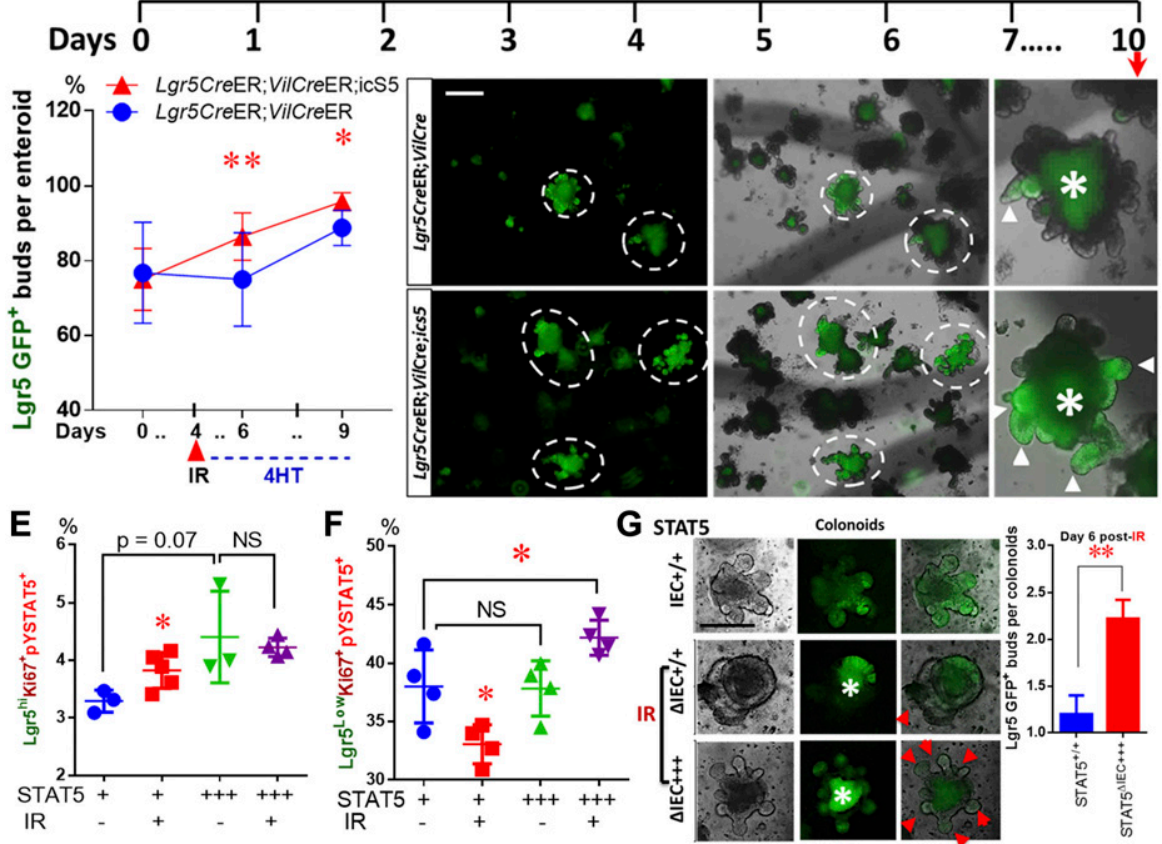

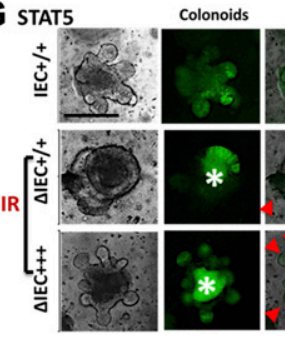

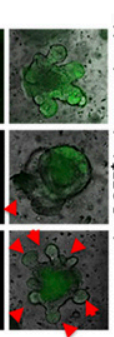

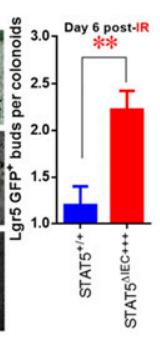

Figure 4. pYSTAT5 restricts Lgr5 ${ }^{\text {low }}$ Ki67 $^{+}$IESCs to give rise to pYSTAT5 ${ }^{+} \mathrm{Lgr5}^{-} \mathrm{CD}^{-} 4^{+}$Paneth cells.

Intestinal crypts were extracted from Lgr5CreER; VilCreER;Stat5 or icS5 and dissociated with TrypLE into IECS. Lgr5-, low and high IECs were then separated by gating with FACS (Fig S5A). (A) APC-conjugated pYSTAT5 and $\mathrm{PE}$-conjugated $\mathrm{CD} 24$ staining were used to quantitate pYSTAT5 ${ }^{+}$Lgr5 ${ }^{-}$CD2 $4^{+}$cells (P1) or $\mathrm{Lgr5}^{-} \mathrm{CD} 24^{+}$ Paneth cells (P2). (B) Lgr5 ${ }^{\text {hi }}:$ CD2 $24^{+}$doublets in the dissociated IECS were determined by FACS. $n=4$ or 5 mice per group, ${ }^{* *} P<0.01$ versus STAT5 ${ }^{+/+}$. (C) The dissociated IECs were immunostained with CD24, and co-localization of Lgr5 and CD24 was determined with a confocal microscope. Lgr5:CD24 doublets are shown as circles. (D) Lgr5-GFP crypts from Lgr5CreER or Lgr5CreER; VilCreER;icS5 mice were employed for IESC culture for $4 \mathrm{~d}$, and pYSTAT5 was inducibly activated by $4 \mathrm{HT}$ (200 $n M$ ) after one dose of $y$-irradiation (IR). The numbers of Lgr5-GFP buds were counted in each well, and budding curve was created $6 \mathrm{~d}$ after $4 \mathrm{HT}$ treatment. ${ }^{*} P<0.01$ and ${ }^{*} P<0.05$ versus controls without $4 \mathrm{HT}$ induction. Representative images of Lgr5GFP ${ }^{+}$buds (arrows) in the enteroids (circles) are shown, *Autofluorescence. (E, F) Lgr5-GFP enteroids were dissociated into IECS. Lgr5 $^{\text {hi }}$ Ki67 $^{+}$pYSTAT5 $^{+}$(E) and Lgr ${ }^{\text {low }}$ Ki $67^{+}$pYSTAT5 $^{+}$(F) were determined. ${ }^{*} P<0.05$ versus enteroids from Lgr5CreER;VilCreER, ${ }^{\circ} P<0.05$ versus enteroids from IRtreated Lgr5CreER;VilCreER, $\mathrm{n}=$ 4-5 mice per group. (G) Colonic crypts were isolated and differentiated into colonoids. These colonoids were induced by $4 \mathrm{HT}$ for $4 \mathrm{~d}$ and then irradiated at 4 Gy for $10 \mathrm{~min}$. Lgr5 (green) buds are shown; arrowheads indicate crypt budding. GFP crypt buds were counted per colonoids $(n \geq 20)$ from each of six wells from three independent experiments. All results are expressed as mean $\pm S E M$, and $t$ tests and ANOVA were used to compare the significance of a difference. regeneration, possibly by increasing $L g r 5^{\text {low }}$ Ki67 $^{+}$IESC activation or differentiation towards niche cells.

\section{pYSTAT5 protects Lgr5 ${ }^{\text {hi }} \mathrm{Ki} 67^{+}$IESCs from inflammatory cytokine or toxin-induced IEC injuries by enhancing niche function}

In vivo studies showed that inflammatory cytokines and toxins may induce IESC apoptosis or cause Paneth cell degeneration (Farin et al, 2014; Nakanishi et al, 2016); however, whether inflammatory bacterial toxins directly injure IESCS remains unclear. Constitutive PYSTAT5 increased IESC regeneration (Gilbert et al, 2015); thus, we treated enteroids from Rs26tdTomato;icS5 with TNFa $(100 \mathrm{ng} / \mathrm{ml})$, toxin $A(T c d A, 0.5 \mu \mathrm{g} / \mathrm{ml})$, or different doses of toxin B (TcdB; 12, 24, or $36 \mathrm{ng} / \mathrm{ml}$ ). Based on bud numbers (arrows), we categorized enteroid morphology as 1 bud $\left(\mathrm{Org}^{1}\right), 2$ buds $\left(\mathrm{Org}^{2}\right)$, greater than 3 buds $\left(\mathrm{Org}^{3+}\right)$ and spheres (circles) (Figs 5A and S6A). We found that TNF $\alpha$ stimulation increased sphere numbers and size, whereas it reduced budding numbers and enteroid survival (Figs 5A, S6A, and B). For example, TNF $\alpha$ diminished enteroids with over 3 buds $\left(\mathrm{Org}^{3+}\right.$ ) (Fig 5A). In contrast, the activation of STAT5 decreased sphere numbers and increased buds in the TNF $\alpha$-treated enteroids (Fig 5A), suggesting that activated STAT5 may counteract TNF $\alpha$ induced inhibition of IESC niche regeneration. We next exposed enteroids to different doses of TcdB. The budding curves were created to represent the average buds per enteroid at different time points ( $n \geq 20$ enteroids per well, six wells per mouse, and three mice per group). ANOVA was used to compare the difference between groups. We found that a high dose of $\operatorname{TcdB}(36 \mathrm{ng} / \mathrm{ml})$ led to a significant reduction in crypt budding in the Lgr5-GFP enteroids (Fig $5 B-I,{ }^{* *} P<0.01$ versus control). In contrast, inducible activation of icS5 partially restored enteroid proliferation and viability from TcdB cytotoxicity, which were determined by the number of $\mathrm{Lgr5}^{+}$buds per enteroids and Methylene Blue staining (Fig 5B-II and C, ${ }^{*} P<0.05$ versus Con $+30 \mathrm{ng} / \mathrm{ml}$ TcdB). These data suggest that the forced PYSTAT5 protect enteroids from TcdB-induced inhibition of IESC regeneration or niche activity.

Furthermore, using FACS, we found that TcdB not TcdA treatment led to increased Lgr5 $^{\text {hi }} \mathrm{Ki} 7^{+}$apoptosis (Fig 5D) and reduced Lgr5 ${ }^{\text {hi }} \mathrm{Ki} 67^{+}$proliferation (Fig 5E). In contrast, the activation of STAT5 reduced $\mathrm{Lgr5}^{\text {hi }}$ or $\mathrm{Lgr5}^{\text {low }} \mathrm{BrdU}^{+}$IESC apoptosis induced by TcdB (Fig 
A
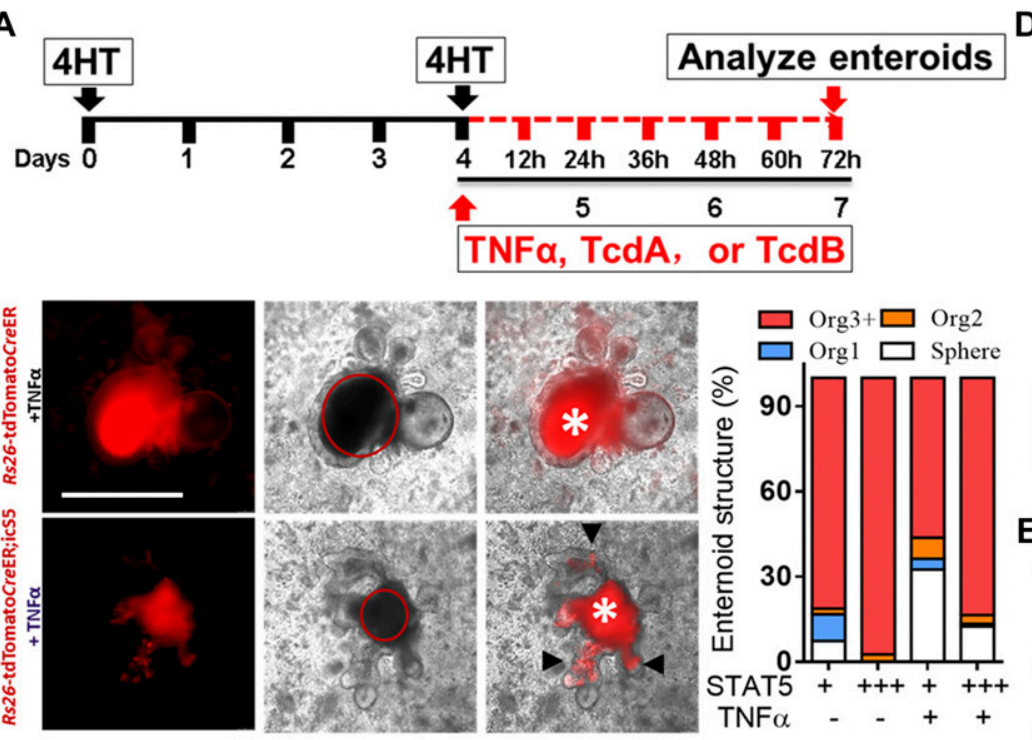

B
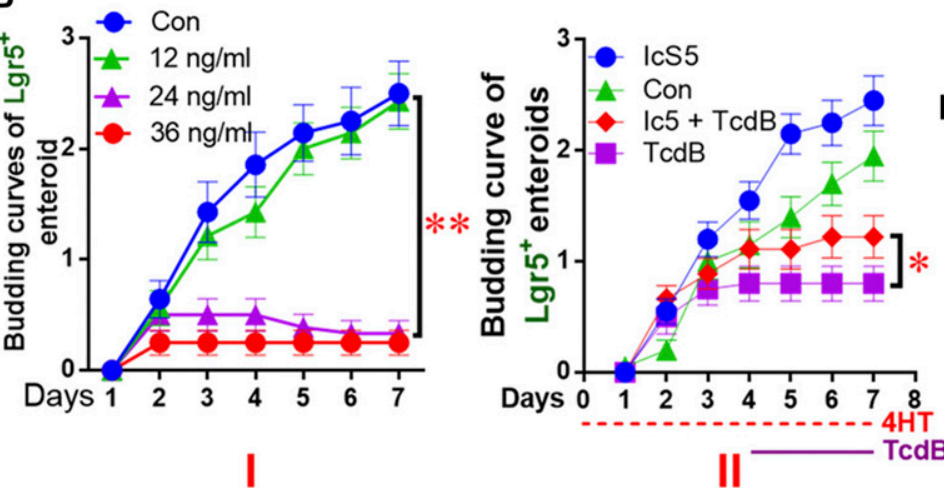

C

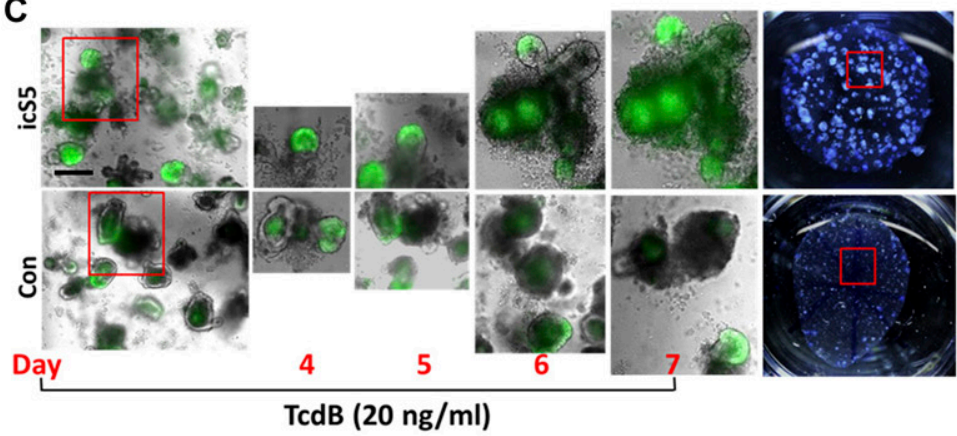

H Days
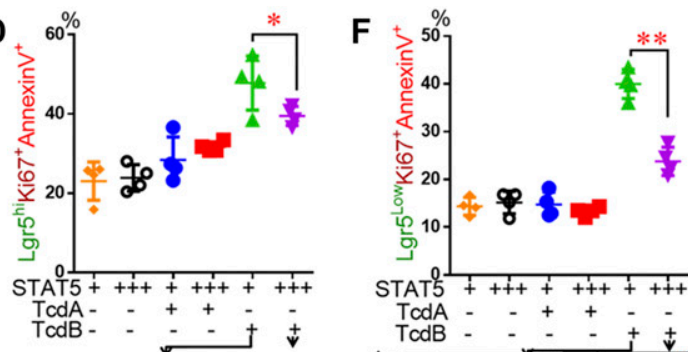

$\operatorname{Tcd} A$

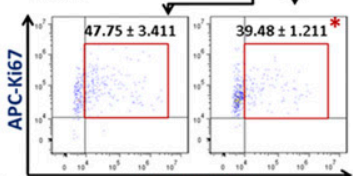

E
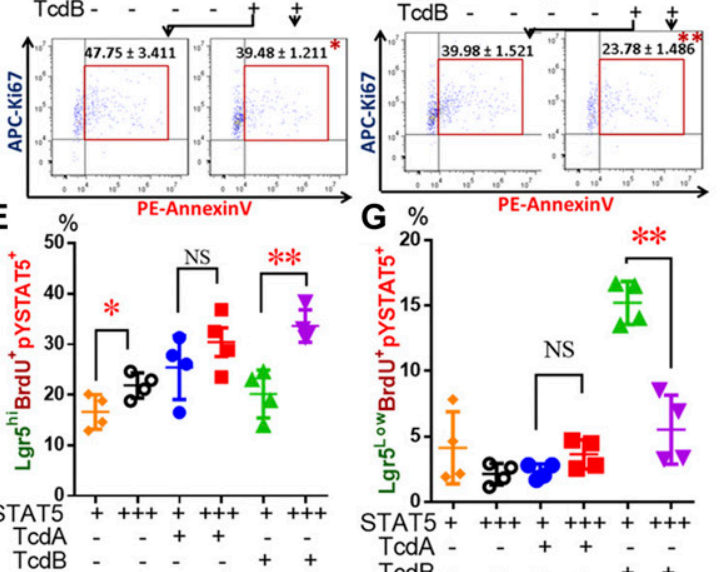

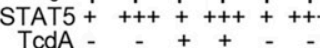
TcdB - - - - + +

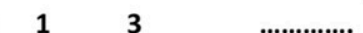

7

9

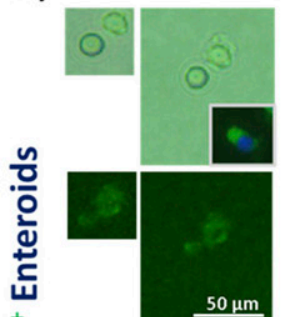

+ Conditioned medium ( $R$ Spondin-1 EGF Noggin Wnt3a)

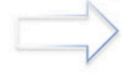
㞱
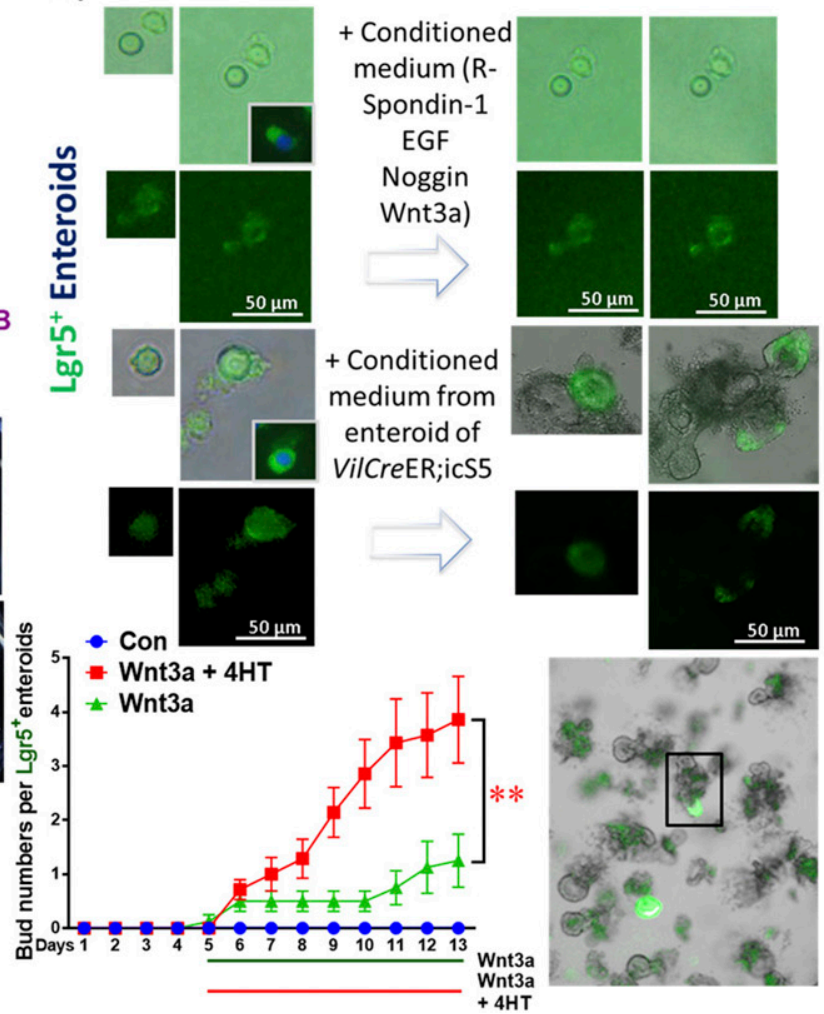

Figure 5. pYSTAT5 protects Lgr5 ${ }^{\text {hi }}$ Ki $7^{+}$IESCs from inflammatory cytokine- or toxin-induced IEC injuries by enhancing niche function.

(A) Enteroids were cultured. PYSTAT5 was induced with $4 \mathrm{HT}$ for $4 \mathrm{~d}$, then exposed to TNFa, TcdA, or TcdB for $3 \mathrm{~d}$. Enteroids were cultured from intact intestinal crypts dissociated from Rs26-tdTomatoCreER and Rs26-tdTomatoCreER;icS5 mice. Based on the number of buds, enteroid morphology was categorized as follows: 1 bud $\left(\mathrm{Org}^{\top}\right), 2$ buds $\left(\mathrm{Org}^{2}\right)$, greater than 3 buds $\left(\mathrm{Org}^{+}\right)$and no buds (Sphere). Results were expressed as mean $\pm \mathrm{SEM}, \mathrm{n}=4$ or 5 mice per group. *Autofluorescence. (B) Enteroids from Lgr5CreER;VilcreER and Lgr5CreER;VilcreER;icS5 were cultured, then were treated with TcdB (I). After icS5 was induced on day 4, enteroids were treated with $30 \mathrm{ng} / \mathrm{ml}$ TcdB for $3 \mathrm{~d}$ (II). (C) Representative images of Lgr5 enteorids from days 4 to 7 with or without TcdB or icS5 induction are shown. These treated enteroids were then dissociated for FACS. (D, E) APC-conjugated AnnexinV and PE-conjugated pYSTAT5 were used to determine the effects of pYSTAT5 upon Lgr5hiki67 ${ }^{+}$proliferation or

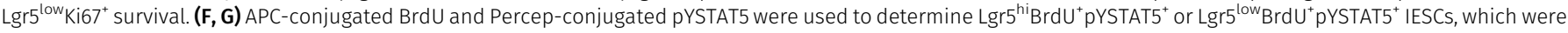


$5 \mathrm{D}$ and $\mathrm{F}$ ) and stimulated $\mathrm{Lgr}^{\mathrm{hi}} \mathrm{BrdU}^{+} \mathrm{IESC}$ proliferation (Fig 5E) and repressed $\mathrm{Lgr}^{\text {low }}{ }^{\mathrm{BrdU}}{ }^{+} \mathrm{IESC}$ proliferation (Fig 5G). Taken together, these data suggest that pYSTAT5 prevents IESCS from TCdB inhibition by protecting $\mathrm{Lgrh}^{\mathrm{hi}} \mathrm{BrdU}^{+}$IESCS or enhancing switching from $\mathrm{Lgr5}^{\mathrm{hi}} \mathrm{BrdU}^{+} \rightarrow$ to $\mathrm{Lgr5}^{\text {low }} \mathrm{BrdU}^{+}$IESCS for niche regeneration.

Finally, utilizing the conditioned feeding medium made from WT or VilCreER;icS5 ileal enteroids, we transferred the conditioned

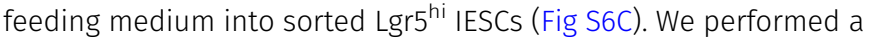
"medium replacement" experiment to study whether the factors

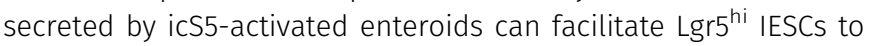
differentiate as enteroids (Fig $5 \mathrm{H}$ ). Incubation with medium from icS5 ileal enteroids (Wnt3a $+4 \mathrm{HT}$ ) significantly increased Lgr5 ${ }^{\text {hi }}$ IESC proliferation compared with conditioned medium made from WT enteroids ( $P<0.01$ versus Wnt3a group), indicative of a role of PYSTAT5 or PYSTAT5-derived factors secreted by icS5 enteroids on the niche. In contrast, by counting the percentage of the final survival enteroids versus initial grown enteroids in the presence or absence of TNF- $\alpha$ (Schewe et al, 2016), our results showed that the reduced STAT5 by partially depleting Stat5 significantly impaired the regenerative capacity of enteroids, displaying a compromised organoid formation manifested by the diminished bud numbers, enlarged spheroid size, and reduced survival of organoids, the phenotypes of which are significantly exaggerated by the presence of TNF- $\alpha$ (Fig S6A and B). Taken together, our data indicated that PYSTAT5 may restrict Lgr5 $^{\text {low }}$ Ki67 $^{+}$IESCS to give rise to pYSTAT5 ${ }^{+}$ Lgr5 ${ }^{-}$CD $24^{+}$Paneth cells, which protect Lgr5 ${ }^{\text {hi }}$ IESCS from inflammatory cytokines or enteric toxin-induced IESC injuries, whereas reduced PYSTAT5 impairs the regenerative capacity of the enteroids in homeostasis and inflammation conditions.

\section{Constitutive pYSTAT5 enhances heterogeneous monolayer integrity and increases Lysozyme production in human intestinal organoids (HIOs)}

We generated iPSCs stably expressing wild-type (WT-GFP), inducible active forms of STAT5A (STAT5a-ER) and inducible constitutively active STAT5 (icS5-ER) (Gilbert et al, 2015). In these iPSCS, pYSTAT5 can be inducibly or persistently activated in a dose-dependent manner (Fig S7A). Transduced iPSCs are able to be differentiated into HIOs (Spence et al, 2011). These HIOs were cultured under conditions that promote intestinal growth, morphogenesis, and cyto-differentiation into functional intestinal cell types including enterocytes, goblet cells, Paneth cells, and enteroendocrine cells (Fig 6A) as previously reported (Spence et al, 2011). iPSC-derived HIOs contain undifferentiated progenitors or fetal-like stem cells that could maintain HIO regeneration during injury (Spence et al, 2011; Watson et al, 2014). Therefore, HIOs represent a novel human primary cell model system that can be used for studying IESC regeneration-dependent IEC repair as summarized by the Wells group (Sinagoga \& Wells, 2015). Our data showed that 2-mo HIOS contained heterogeneous monolayers with fully differentiated IECS
(Paneth, goblet, enterocyte, and enteroendocrine cells) with intercellular junctional barriers (Figs 6A and S7C) (Spence et al, 2011; Watson et al, 2014). We next differentiated lentivirus-transduced iPSCs into HIOs after $2 \mathrm{mo}$ in culture and assessed $\mathrm{HIO}$ lineage integrity by measuring the efflux of microinjected fluorescein isothiocyanate-dextran 4 (FD4) and transepithelial electrical resistance (TEER) (Figs 6B and S7B). We found that TcdB impaired HIO lineage integrity during early time treatment (within 6-h of treatment) but not TcdA, while Cytomix (IFNy and TNF $\alpha$ ) led to disruption of $\mathrm{HIO}$ cell integrity and leaky junctions after $24 \mathrm{~h}$ of treatment. In contrast, persistent PYSTAT5 induced by icS5-ER, but not transient PYSTAT5 induced by STAT5a-ER, restored HIO lineage integrity following Cytomix treatment (Fig 6B). This persistent pYSTAT5 also resulted in an up-regulated $\beta$-catenin expression, increased $\mathrm{LGR5}^{+}$ IECS, expression of inter-cellular junctional proteins (E-cadherin, occludin, ZO-1, and ZO-2), and Lysozyme expression and inhibited quiescent IESC markers Bmi1 and Dclk1 (Figs 6C and S7C). These data suggest that icS5-induced persistent PYSTAT5 expression repairs leaky HIOs by enhancing $\mathrm{HIO}$ de novo differentiation to promote heterogeneous monolayer maturation.

\section{Constitutive pYSTAT5 induces de novo niche differentiation to protect IESC regeneration}

Transplantation of HIOs into the kidney capsules of immunodeficient NOD-Scid IL2Rynull (NSG) mice has previously been used to evaluate functional engraftment of tissues, IESC-regenerative repair, and IEC lineage differentiation (Watson et al, 2014). We implanted HIOs that were differentiated for 2 mo into the kidney capsule (Fig 6D) and allowed them to develop into intestinal tissue according to the published protocols (Spence et al, 2011; Watson et al, 2014) (Fig 6E). We found that inducible activation of icS5 significantly increased $\mathrm{AsCl}^{+}$and $\mathrm{Lgr5}^{+} \mathrm{CBC}$ proliferation (Fig 6E), suggesting a direct effect of persistent pYSTAT5 signaling on increasing numbers of Lgr5 IESCS. Using a knock-in and Taminducible cre recombinase to facilitate tracing of the lineage of a single human LGR5 stem cell during HIO development (Fig 6F) we found that the activation of icS5 yielding a persistent PYSTAT5 in transplanted HIOs significantly enhanced LGR5 GFP lineage tracing (Fig 6G), and Lyso ${ }^{+}$Paneth and Muc2 ${ }^{+}$goblet cells at crypt bases in the transplanted $\mathrm{HIO}$-derived intestinal tissues (Fig $6 \mathrm{H}$ ). After exposing the transplanted mice to $5 \mathrm{~d}$ of Tam following $5 \mathrm{~d}$ of Cre recombination, we then exposed the transplanted NSG mice to one dose of 12 Gy irradiation and tested the function of engrafted IESC activation for regenerative repair $3 \mathrm{~d}$ post-irradiation. Persistent PYSTAT5 resulted in well-preserved regenerated crypts compared with transient pYSTAT5, which exhibited few nascent crypts $3 \mathrm{~d}$ post-irradiation (Fig 6I). Taken together, our data strongly suggest that the activation of icS5 increases IESC regenerative capacity, possibly through de novo enhancement of Paneth cell niche formation to maintain IESC regeneration.

used to quantitate Lgr5 $^{\text {hi }}$ or Lgr5 ${ }^{\text {low }}$ IESC proliferation, $\mathrm{n}=4-5$ mice per group. $(\mathrm{H})$ Lgr5 ${ }^{\text {hi }}$ IESCS were sorted from Lgr5CreER mice or Lgr5CreER;icS5 mice and enteroids were cultured. Conditioned medium was generated from enteroids from VilCreER;icS5 mice. Lgr5 ${ }^{\text {hi }}$ IESCS were sorted and grown into enteroids to compare the effects of the conditioned medium versus regular medium on Lgr $5^{\text {hi }}$ single cell growth and enteroid differentiation. All results are expressed as mean \pm SEM and $t$ tests and ANOVA were used to compare the significance of a difference. 
A
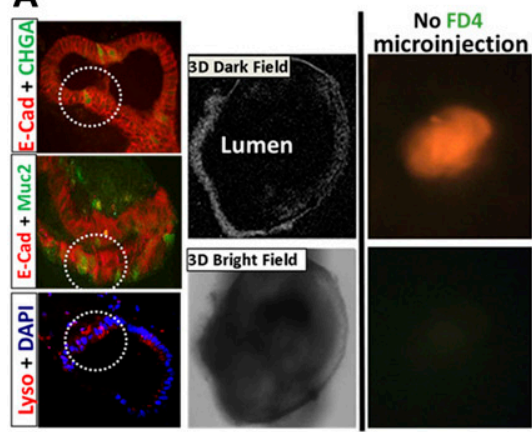

C

$$
\begin{array}{lllll}
+ & + & - & - & \text { STAT5a-ER } \\
- & - & + & + & \text { icS5-ER } \\
- & + & - & + & \text { 4HT }
\end{array}
$$

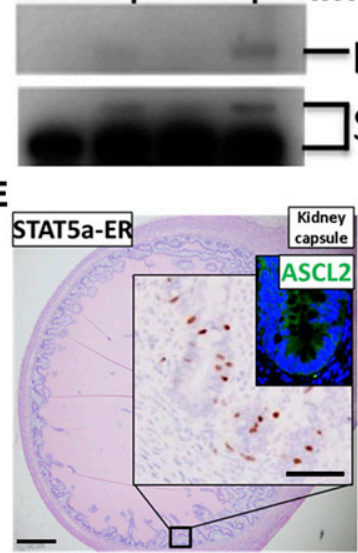

- PYSTAT5 STAT5A

\section{D mo}
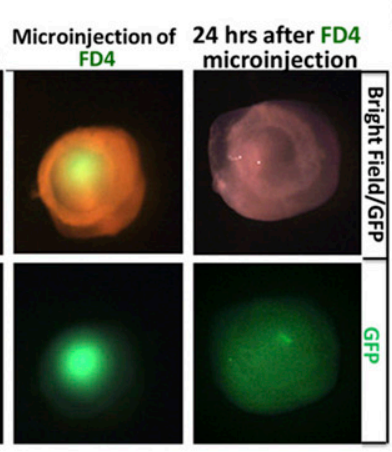

HIOs

4HT Microinjection of TNF $\alpha$, TcdA
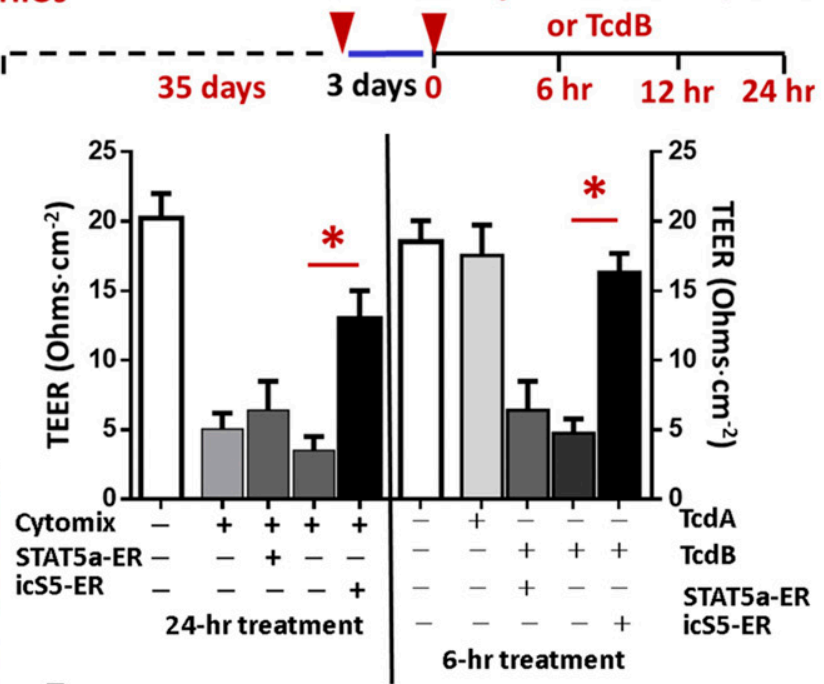

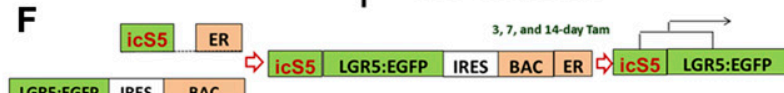

G
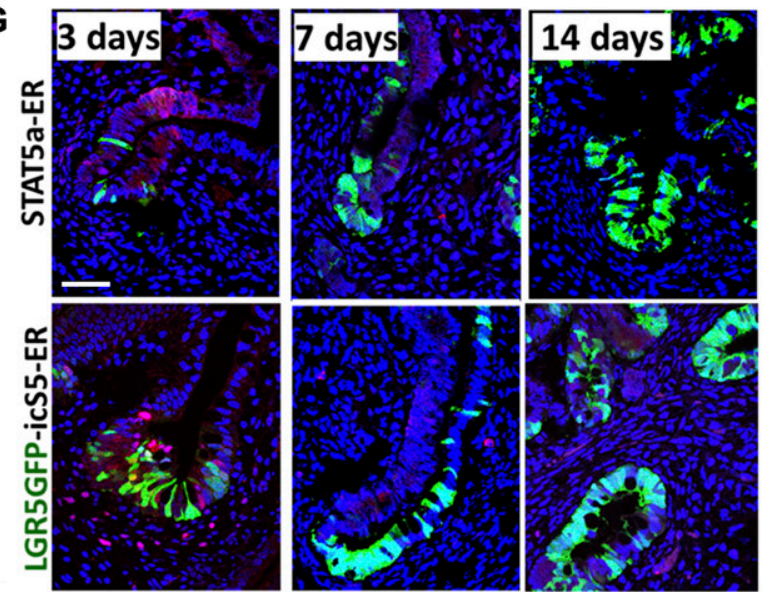

H $A B$
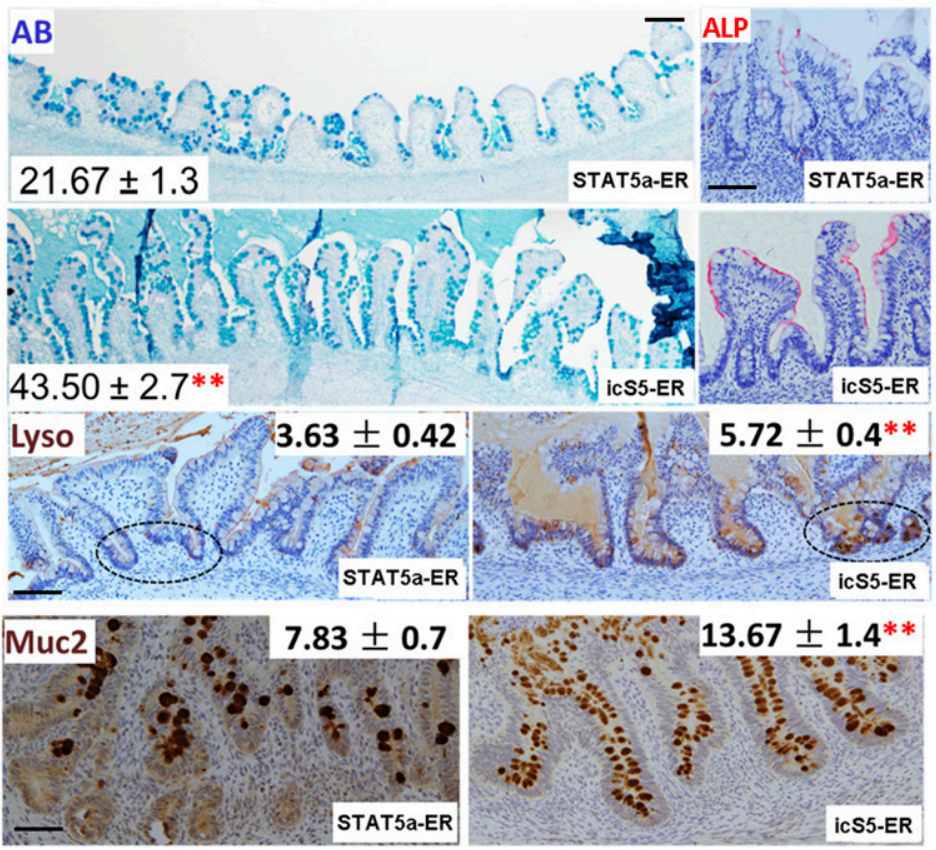

I

$$
\begin{array}{ll}
\text { STAT5a-ER* } & + \\
\text { ic5-ER* } & -
\end{array}
$$

icS5-ER*
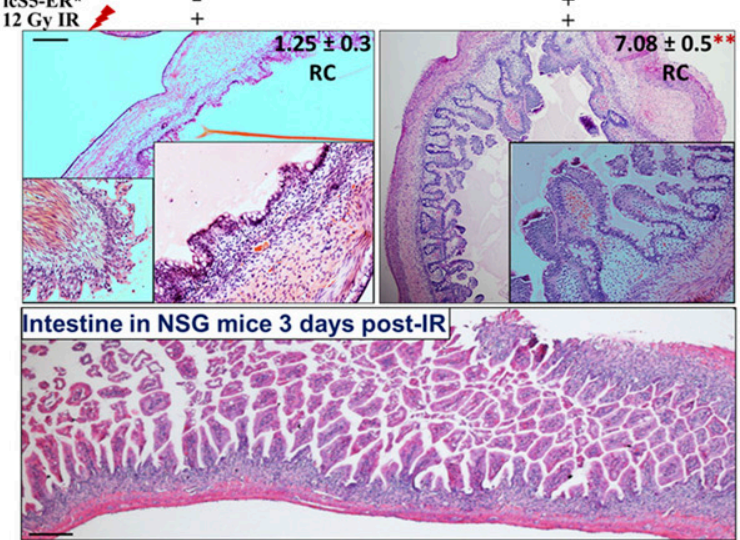

Figure 6. Constitutive pYSTAT5 induces de novo niche differentiation and protects IESC regeneration.

iPSCS or LGR5:eGFP BAC reporter iPSCS were transduced with a lentiviral GFP construct for STAT5a-ER and icS5-ER mutant. HIOs were in vitro matured for 35 d. (A) Transduced HIOs were imaged under 3D in vitro culture systems with dark-field and bright-field 3D confocal deconvolution microscopy. IEC types in HIOs were determined by double-IF, E-Cadherin (E-Cad) + Chromogranin A (CHGA) or E-Cad + Muc2, and Lyso IF staining. (B) Transduced HIOs were then microinjected 250 ng FD 4 (FD4) with $0.25 \mathrm{ng}$ TNF $\alpha(100 \mathrm{ng} / \mathrm{ml})$ or $25 \mathrm{ng}$ TcdA or $50 \mathrm{ng}$ TcdB after 3-d 4HT induction. HIO integrity was determined as the TEER after 24-h TNF $\alpha$ or 6-h TcdA or 
STAT5 activation regulates Wnt- $\beta$-Catenin-Sox9 signaling axis to sustain niche cell differentiation in a stepwise manner

To determine the potential molecular mechanisms by which STAT5 signaling controls niche cell homeostasis, we isolated total RNA from intact intestinal crypts of STAT5 ${ }^{+/}$, STAT5 $5^{\Delta I E C-I_{-}}$, and STAT5 ${ }^{\triangle I E C+++}$ mice and performed RNA sequencing (RNA-seq). The sample correlation matrix and hierarchical clustering based on the correlation

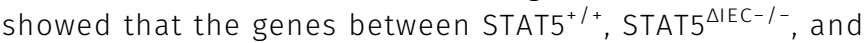
$\mathrm{STAT5}^{\Delta \mathrm{EC}+++}$ mice were clustered separately. Furthermore, the altered gene signatures of intestinal crypt IECs were correlated with Stat5 depletion or PYSTAT5 activation $(P<0.05$ and fold change $>2$ in at least one pairwise comparison of 691 genes, Fig 7A). Scatter plots of the log2 (fragments per kilobase of exon model per million reads mapped (FPKM)) counts of genes with a cutoff of 1.0 for the absolute value of log2 (ratio) of expression levels showed greater than onefold significant changes in differential gene expression between STAT5 ${ }^{\Delta \mathrm{IEC}-I_{-}}$and $\mathrm{STAT}^{+/+}$mice and between STAT5 ${ }^{\triangle \mathrm{EEC+++}}$ and $\mathrm{STAT}^{+/+}$mice (Fig 7B). Venn diagrams showed that shared and unique genes were differentially expressed in STAT5-deficient or PYSTAT5-activated crypt IECS. Of these genes, 184 were up-regulated genes in STAT5 ${ }^{\triangle I E C+++}$ mice compared with $\mathrm{STAT5}^{+/+}$mice, and 52 were down-regulated genes in STAT5 $5^{\Delta \mathrm{EC}-/-}$ mice compared with $\mathrm{STAT5}^{+/+}$mice. Furthermore, we observed 54 down-regulated and 85 up-regulated genes specific to STAT5 ${ }^{\triangle I E C-1-}$ mice, and 122 upregulated and 126 down-regulated genes specific to STAT5 ${ }^{\triangle \mathrm{EC}+++}$ mice (Fig S8A).

Gene ontology enrichment analysis of these identified genes indicated that PYSTAT5 activation in IECS up-regulated intestinal innate immunity, cytokine production, IFNY, and autophagy, and down-regulated chromatin silencing, susceptibility to infection, and DNA damage-induced senescence (Fig S8B). These findings indicate that PYSTAT5 activation enhanced intestinal secretion and innate immune reaction to acute infection. In contrast, the depletion of Stat5 exaggerated immune response, inflammation, and wounding responses and decreased Th2-associated cytokines IL-10, IL-7, and thyroid peroxidase and IL-3 anti-inflammatory JAK-STAT signaling (Fig S8C), suggesting the suppression of Th2 immune induction or crypt cell activation. These identified differentially expressed genes were then subjected to Ingenuity Pathway Analysis. Inflammatory pathways such as TNF $\alpha$, IFNy, IL-4, IL-13, and IL-10 or IL-22 inflammatory or anti-inflammatory pathways were enriched in STAT5 ${ }^{\Delta \mathrm{EE}-1-}$ and STAT5 ${ }^{\triangle I E C+++}$ compared with STAT5 $^{+/+}$mice (Fig S8D). These data suggest that STAT5 proteins in crypt IECS are essential for intestinal immune and inflammatory responses. Furthermore, these data suggest that STAT5 signaling regulates intestinal inflammation responses to shape innate immune development.
Next, we studied the genes and pathways downstream of STAT5 signaling to elucidate the molecular mechanisms of STAT5 restriction of crypt Paneth cell fates from progenitors. Constitutive Wht signaling allocates Paneth cells along the crypt base to the villus (van Es et al, 2005). Intriguingly, toxin B was found to compete with Wnt signaling to bind Frizzled (FZD) family of receptors to mediate colonic epithelial injury (Chen et al, 2018). These results indicated that $C$. difficile toxins may cause intestinal injury by impairing Wnt signaling-dependent Paneth cells. Using hierarchical clustering of averaged normalized expression, we found that inducible activation of intestinal PYSTAT5 significantly regulated the key Wnt signaling pathway genes. These genes, Fzd5-Ctnnb1-Tcf4 (Tcf7L2)-Sox9, Gfi1, and EphB2/3, were differentially regulated in

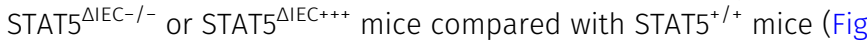
$\mathrm{S} 8 \mathrm{E})$. Interestingly, other key genes that regulate Paneth cell functions were also significantly altered, such as anti-microbial Defa5, metabolic and inflammatory Lcn2 (Vijay-Kumar et al, 2010), autophagy-related Xbp1 (Kaser et al, 2008), and ER protein Agr2 (Zhao et al, 2010) that regulate Paneth cell functions were also significantly altered $\left(P<0.001\right.$ STAT5 $^{\Delta \mathrm{EC}+++}$ and STAT5 ${ }^{\Delta \mathrm{ECC}-/-}$ versus $\mathrm{STAT}^{+/+}$mice, Fig S8E). Consistently, we found that pYSTAT5 in STAT5 ${ }^{\Delta \mathrm{IEC}+++}$ mice markedly increased nucleic $\beta$-catenin and Sox9 in IECS at the crypt bases compared to controls (Fig 7C and D). We then measured the induction of PYSTAT5 levels in icS5-transduced HIOs with different doses of $4 \mathrm{HT}$. Our results showed that PYSTAT5 induction in HIOs appeared 4HT dose-dependent from 10 to $200 \mathrm{nM}$ and enhanced $\beta$-catenin expression (Fig 7E). A stepwise $\beta$-cateninTcf4-Sox9 pathway is the key pathway for determining Paneth cell commitment in the crypt progenitor fate towards niche differentiation (Mori-Akiyama et al, 2007). Accordingly, our data suggest that pYSTAT5 activation is essential for the differentiation of intestinal niche cells, likely Paneth cells. STAT5 may be a critical lineage-specific transcription factor that regulates intestinal niche differentiation and regeneration as well as antiinflammatory or infection functions.

\section{Discussion}

C. difficile infection causes diarrhea and pseudomembranous colitis, which are strongly associated with increased inflammation severity in IBD (Berg et al, 2013). While it remains unknown whether C. difficile infection has a causal link with IBD (Monaghan et al, 2015), a recent multi-center study defined a baseline prevalence of $7.5 \%$ for $C$. difficile infection amongst pediatric IBD patients compared with only $0.8 \%$ for controls with celiac disease (Martinelli et al, 2014).

\footnotetext{
TcdB treatment. Results are expressed as mean \pm SEM. ${ }^{*} P<0.05$ versus control HIOs. $n \geq 4$ HIOs per group. (C) NEs were extracted from single HIOs, and pYSTAT5 and STAT5 were measured using immunoblotting. $n \geq 4$ HIOs per group. (D) Transduced HIOs were matured and then transplanted beneath the kidney capsule of NSG mice. Tam induction was performed for $5 \mathrm{~d}$ 1-mo post-engraftment. (E) Proliferation of transplanted IESCS was determined with anti-Ascl2 and BrdU IH in the presence and absence of icS5 activation, $n=5$ per group. $(F, G)$ LGR5:eGFP BAC reporter iPSCS were transduced with lenti-viral STAT5a-ER or icS5-ER. 3, 7, or 14 d after one dose of Tam, transplanted mice were euthanized. Transplanted HIOs were stained with GFP IF, and IESCS were labeled with LGR5-GFP and EdU. icS5 activation increased LGR5 IESCS and enhanced LGR5 lineage tracing compared with that in STAT5a-ER. $n \geq 3$ mice per group. (H) Transplanted HIOs were stained with AB, Alkaline phosphatase (ALP), Lyso, and Muc2 $\mathrm{IH} . ~ A B^{+}$, Lyso ${ }^{+}$, or Muc2 ${ }^{+}$crypt cells were counted as average numbers per crypt. 100 well-orientated crypts were chosen from five mice per group, ${ }^{\star \star} P<0.01$ versus STAT5a-ER. (I) Some of the transplanted mice were subjected to 12-Gy irradiation. Regenerated crypts (RC) were counted in the transplanted HIOs. Inserts are the images at a higher-magnification. Intestines from the irradiated mice show no RC. ${ }^{*} P<0.01$ versus STAT5a-ER, $n \geq 5$ mice per group, Scale $=200 \mu$ m. All results are expressed as mean \pm SEM, and $t$ tests and ANOVA were used to compare the significance of a difference.
} 


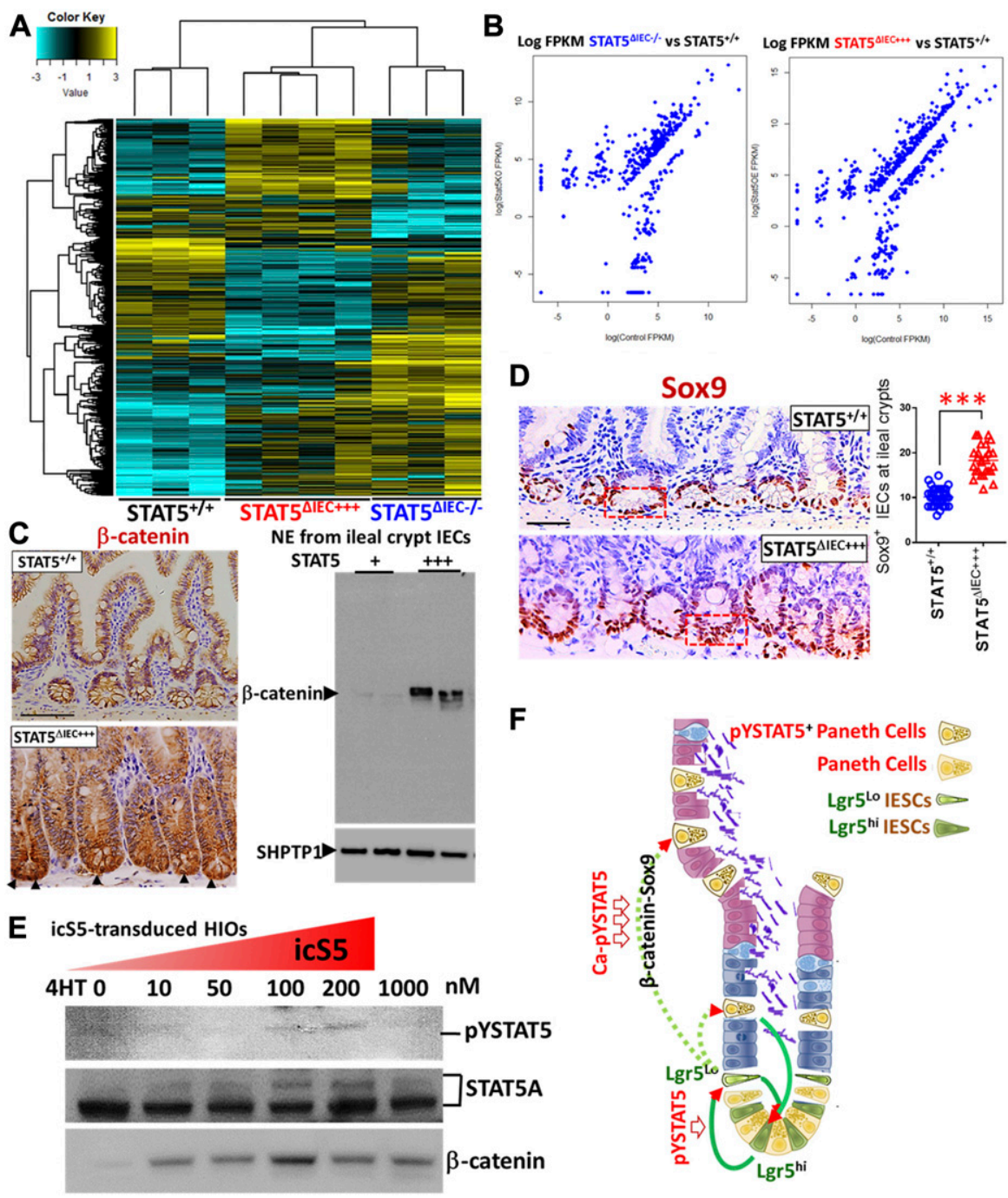

Figure 7. STAT5 activation enhances IESC niche differentiation by regulating the IESC transcriptome. (A) Hierarchical clustering of 691 genes with ANOVA P < 0.05 and fold change $>2$ in at least one pairwise comparison between $\mathrm{STAT5}^{+/+}$, STAT5 ${ }^{\Delta \mathrm{EC}-1-}$, and STAT5 ${ }^{\Delta \mathrm{EC}+++}$ mice, using Pearson's centered distance metric and average linkage rule. (B) Scatterplots of log (FPKM) of differentially regulated genes in STAT5 ${ }^{\triangle \mathrm{ECC}-l-}$ and STAT5 ${ }^{\Delta \mathrm{ECC+++}}$ mice when compared to STAT5 ${ }^{+/++}$ mice. (C) $\beta$-catenin was determined by $\mathrm{IH}$ and immunoblotting with NE from intestinal crypts. Results are expressed as mean $\pm S E M, n \geq 3$ mice per groups, and $t$ tests were used to compare the significant difference. (D) Sox9 was immunostained and quantitated in the 200 crypts. Results are expressed as mean $\pm S E M, n \geq 3$ mice per groups, and $t$ tests were used to compare the significant difference. (E) icS5-ER-transduced HIOs were in vitro matured for $35 \mathrm{~d}$. icS5 activation in HIOs was induced with different doses of $4 \mathrm{HT}(0,10,50,100$, or 200 $\mathrm{nM}$ or $1 \mathrm{mM}$ ) for $72 \mathrm{~h}$. PYSTAT5, STAT5A, and $\beta$-catenin were determined by immunoblotting. This experiment was repeated three times. (F) Hypothesis model: pYSTAT5 amplifies Lgr $^{\text {hi }} \rightarrow$ to Lgr5 $^{\text {Low }}$ Ki67 $^{+}$IESCS; CapYSTAT5 promotes Lgr5 ${ }^{\text {low }} \mathrm{Ki} 7^{+}$IESCs to give rise to a sublineage of crypt cells, intestinal pYSTAT5 ${ }^{+}$Lgr5 ${ }^{-}$CD24 $4^{+}$ Lyso $^{+}$Paneth cells by activating Wnt/ $\beta$-catenin/Sox9 pathway.

Furthermore, patients with $\mathrm{C}$. difficile infection were more likely to subsequently require escalation of medical therapy and hospitalization during follow-up. Meta-analysis showed that C. difficile infection was a significant risk factor for colectomy among patients with $I B D$, indicating that $C$. difficile infection may greatly reduce mucosal healing in IBD (Chen et al, 2017). Neither antibiotics, proton pump inhibitors, hospitalization, nor IBD therapies were associated with C. difficile infection (Martinelli et al, 2014). Interestingly, C. difficile can maintain colonization in the intestines, without inducing enteritis or colitis, suggesting an essential role of innate host defenses in the protection from $C$. difficile infection to colitis (Monaghan et al, 2015). Importantly, Paneth cells maintain host-microbiota homeostasis (Zhang et al, 2015a), and as such, genetic defects in Paneth cells induce intestinal inflammation and increase susceptibility to both IBD (Wehkamp et al, 2007) and C. difficile colitis (Giesemann et al, 2008). Together, these reports suggest a crucial role for host factors such as genetic variants, IESC regeneration, or Paneth cell specialization in the $C$. difficile-associated comorbid conditions, such as IBD. Therefore, targeting endogenous IEC repair could decelerate persistent infection progress to IBD.
It has been reported that Lgr5 ${ }^{+}$IESCs at crypt bases are heterogeneous and represent Lgr5 $^{\text {hi }} \mathrm{Ki}_{67}{ }^{+}$, Lgr $^{\text {hi }} \mathrm{Ki}^{6} 7^{-}$, Lgr $^{\text {low }}{ }^{\text {Ki67 }}{ }^{+}$, and Lgr5 $^{\text {low }}$ Ki67 $^{-}$IESCS, and Lgr5 ${ }^{\text {low }}$ Ki67 $^{+}$IESCS are located above Paneth cells and have significantly higher Stat5a mRNA (Basak et al, 2014). These cells can be reactivated toward secretory fates and are also required for regenerating crypts in the presence of severe intestinal damage (Metcalfe et al, 2014), although the required conditions have yet to be established (Basak et al, 2016). Our data indicated that pYSTAT5 induced $\mathrm{Lgr5}^{\text {low }} \mathrm{Ki} 67^{+}$IESCS to give rise to a distinct population of ileal crypt cells, the pYSTAT5 ${ }^{+}$Lgr $5^{-} \mathrm{CD} 24^{+}$cells. In this study, we tested the functions and molecular markers of Lgr $^{\text {low }}{\text { Ki } 67^{+}}^{+}$IESC activation and whether their differentiated progeny play a role in IESC niche regeneration. Our data indicated that PYSTAT5 induced Lgr5 ${ }^{\text {low }} \mathrm{Ki} 67^{+}$IESCS to give rise to a distinct population of ileal crypt cells, the pYSTAT5 ${ }^{+}$Lgr $5^{-} \mathrm{CD} 24^{+}$cells. We concluded that a lack of pYSTAT5 impairs the activation of Lgr5 ${ }^{\text {low }} \mathrm{Ki} 67^{+}$IESCS and reduces IESC niche formation, leading to susceptibility to $C$. difficile toxins and $C$. difficile infection recurrence, perhaps increasing the comorbidity with ileocolitis. In contrast, pYSTAT5 ${ }^{+}$Lgr5 ${ }^{-} \mathrm{CD} 24^{+}$maintains IESCS as niche cells and Ca-pYSTAT5 up-regulates the protective functions of 
the Paneth cell niche through feed-forward amplification of $\mathrm{Lgr5}^{\text {hi }}$ $\rightarrow$ to Lgr5 $^{\text {low }}$ Ki67 $^{+}$IESCS $\rightarrow$ to PYSTAT5 ${ }^{+}$Lgr5 $^{-} \mathrm{CD} 24^{+}$niche cells (Fig 7F). However, our current studies have some limitations: for example, the unclear genetic or epigenetic mechanisms that a persistent pYSTAT5 regulates Wnt/ $\beta$-Catenin signaling to restrict $\mathrm{Lgr5}^{\mathrm{Low}} \mathrm{Ki}^{6} 7^{+}$cells to differentiate into Paneth niche cells. Interestingly, computational analysis displays some STAT5 GAS motifs on $\beta$-Catenin. In the next step of our investigation, besides determining the target genes of PYSTAT5, we will identify the formation of STAT5 tetramer and chromatin remodeling induced by Ca-PYSTAT5, and if the STAT5 tetramers can stabilize intestinal secretory cell differentiation by epigenetically activating or repressing the target genes (Wingelhofer et al, 2018).

Adult IESCS are roughly categorized as either active or quiescent IESCS (Barker et al, 2007; Sangiorgi \& Capecchi, 2008). Interestingly, quiescent IESCS are also labeled as a $\mathrm{Lgr}^{\text {low }} \mathrm{Ki} 67^{+}$or $\mathrm{Bmi}^{+}$population that can be reactivated to differentiate hormone-producing enteroendocrine cells or secretory niche cells (Basak et al, 2014, 2016; Yan et al, 2017). Although whether a dedicated pool of quiescent IESCS exists remains unknown, the two populations of IESCS are believed to be regulated by "naive niche" signaling to dynamically switch, permitting IESCS to continually replenish rapidly proliferating progenitors and various types of IECs to maintain intestinal homeostasis (Barker, 2014). Intestinal inflammatory cells secret a special array of regenerative factors that also lead to an injury-induced niche (Li \& Clevers, 2010): however, the details of these events have not been thoroughly explored. In our previous study, STAT5 signaling is required for IESC differentiation into mature Paneth cells during injury, reflecting the effects of icS5 on IEC plasticity that the immature Paneth cells might be induced to convert into intermediate progenitors or IESCs (Gilbert et al, 2015; Yu et al, 2018). Nevertheless, niche signaling is essential for IESC plasticity to control intestinal homeostasis and is critically involved in diseases, such as infection, inflammation, and tumorigenesis that occur with severely impaired IEC homeostasis (Nakanishi et al, 2016).

The niche cells are required to provide a microenvironment necessary for the maintenance of IESC self-renewal and proliferation, and thus, these cells are in direct contact with intercalated Lgr $^{+}$ IESCS. Depending on the intestinal fragments and injury conditions, niche cells may differ (Sato et al, 2011; Tan \& Barker, 2014). Paneth cells secret Wnt ligands (Wnt3a), EGF, and Notch ligands 1 or 4 (Dll1 or 4) to sustain self-renewal of small intestinal Lgr5 ${ }^{+}$IESCs as well as sense nutrient availability and pathogen invasion by fine-tuning the size of the IESC niche in the small intestine (Tan \& Barker, 2014). Therefore, Paneth cells create specialized crypts as an immune environment that restrains pathogens as well as inflammatory toxins and cytokines from targeting IESCS. However, the underlying mechanisms by which niche interaction with IESCS sustains the regeneration of lineages and controls intestinal inflammation or niche differentiation is induced by injuries are unknown (Ge \& Fuchs, 2018). Our data indicated that persistent PYSTAT5 activation can restrict IESC differentiation to Paneth cell niche, suggesting that a cytokine-context dependency is a crucial determinant in IESC plasticity and niche regeneration. Thus, our further work will be targeted to identify upstream mediators.

Ectopic Paneth cells can be triggered by various physiological stimuli, such as wounding, cancer, or forced activation of stemness factors (van Es et al, 2005). STAT5 is robustly expressed in the intestinal crypt base and TA zone, and furthermore, STAT5 ${ }^{+}$IECS show strong co-localization with Lgr5 $^{+}$intestinal CBCs and crypt niche cells (Gilbert et al, 2015). In this study, we found that persistent icS5 led to Lgr5 $^{\text {low }} \mathrm{Ki67}^{+}$IESCS towards crypt Paneth cell differentiation, crypt fission, and resistance to various injuries. These data strongly suggest an enhanced crypt immunity that maintains IESC clonogenic activity in the icS5 mice. Consistently, the lineage tracing and kidney transplantation experiments showed that PYSTAT5 enhanced Lgr5 IESC activation towards crypt Paneth cell differentiation. Importantly, in vitro niche replacement experiments showed that secretion by icS5, a persistent pYSTAT5, sustained single IESCS as niche to grow more rapidly than conditioned stem cell media. Together, these results indicate that STAT5 maintains the IESC niche and that loss of STAT5 leads to reduced niche activity. Thus, producing the niche factors induced by Ca-pYSTAT5 could provide a novel avenue to treat persistent enteric infection or gut inflammation and reduce antibiotic resistance. Our future studies will test the direct effects of icS5 on Paneth cell function by Paneth cell or DCS-specific Cre recombinase (Zhao et al, 2018).

Collectively, our results have considerable impact on the field as we have defined critical molecular mechanisms by which IESCs are sustained to regenerate in response to acute intestinal damage, thereby informing novel therapeutic approaches for $\mathrm{C}$. difficile infection comorbidity with ileal Crohn's disease, an increasingly common public health problem.

\section{Materials and Methods}

\section{Materials}

All chemicals were purchased from Sigma-Aldrich unless otherwise noted. Antibodies specific for tyrosine phosphorylation-specific STAT5 antibodies (pYSTAT5, Rabbit mAb \#9314), cKit (\#3074), and Phospho-cKit (pckit, \#3391) were purchased from Cell Signaling Technology, antibodies specific for Lgr5 from OriGene (TA503316), antibodies specific for Bmi1 (MAB33341) and ASCL2 (AF6539) from R\&D, antibodies specific for Lysozyme (A0099) and Ki67 (M7249) from Dako, antibodies specific for GFP (ab13970), Dclk1 (ab31704), and another Lgr5 antibodies (ab75850) from Abcam, antibodies specific for STAT5a (71-2400) and STAT5b (71-2500) from Zymed Laboratories (Life Technologies), and antibodies specific for STAT5 and $\beta$-tubulin from Santa Cruz Biotechnology (sc-835). Another tyrosine phosphorylation-specific STAT5 antibody (Tyr642/699) was from Upstate Biotechnology (Cat. No. 05-495). Toxin A (\#152C) and B (\#155A) from C. difficile were purchased from List Biological Labs. Antibodies for FACS analysis are listed in Table S1. For iPSC culture and $\mathrm{HIO}$ maintenance, Matrigel was purchased from BD Bioscience, and human EGF, Noggin, and R-Spondin were from R\&D, advanced DMEM/F12 media were from Life Technologies, and mTeSR1 media were from STEMCELL Technologies. For lentiviral transduction reagents, PLENTI-PGK-Puro-DEST (w529-2) plasmids were from Addgene, iProof High-Fidelity DNA Polymerase was from Life Science Research, and PENTR/D-TOPO cloning kit from Life Technologies. BrdU in situ detection kit was purchased from BD 
Biosciences. Click-iT EdU Alexa Fluor 647 FACS and Imaging kits were purchased from Life Technologies. For adult IESC-derived enteroid culture, Matrigel (Cat. No. 356237) was purchased from BD Bioscience, and murine Wnt3a (Cat. No. 1324-WN), EGF (Cat. No. 2028EG-200), Noggin (Cat. No. 1967-NG-025/CF), and R-spondin (Cat. No. 3474-RS-050) were from R\&D Systems. Y27632 was from Stem Cell Technology (Cat. No. 129830-38). Advanced DMEM/F12 media (Cat. No. 12634-010) was from Life Technologies. TRIzol, Applied Biosystems SYBR Green master mixes, and TrypLE cell dissociation reagents were from Thermo Fisher Scientific.

\section{Animal resources and maintenance}

The animal study protocols have been approved by the Institutional Animal Care and Use Committee (IACUC) of Children's Hospital Research Foundation (CHRF), Cincinnati, USA, and Institute of Laboratory Animal Sciences (ILAS), Beijing, P.R. China. Villin-CreER ${ }^{T 2}$ (VilCreER), icS5, or Stat5 ${ }^{\mathrm{f} / \mathrm{f}}$ mice were maintained and bred in $\mathrm{Pl}$ laboratories at Cincinnati and in Beijing (Gilbert et al, 2012a, 2015). Rosa26-CreER ${ }^{\mathrm{T} 2}$ (Rs26CreER), Rosa26-tdTomato-CreER ${ }^{\mathrm{T2}}$ (Rs26tdTomato), Lgr5 reporter mice (Lgr5-EGFP-IRES-CreER ${ }^{\mathrm{T2}}$, Lgr5CreER), Rosa26CreER-mT/mG (Rosa $\left.{ }^{m T / m G}, 007576\right)$, Villin-Cre (VilCre), and C57BL/ 6 transgenic mice were initially purchased from Jackson Labs. Rosa26-LacZ-CreER ${ }^{T 2}$ (Rs26-LacZ, N5-1819) were purchased from (Shanghai Model Organism, Shanghai). Constitutive or inducible depletion of STAT5 in IECS was achieved by breeding Stat5/f mice with VilCre or VilCreER transgenic mice (el Marjou et al, 2004). Lgr5CreER and Rs26-tdTomato mice were crossed for tracing the progenies of Lgr5 ${ }^{+}$IESCS (Lgr5-tdTomato), and then Lgr5-tdTomato mice were crossed with Stat $5^{f / f}$ or icS5 mice (Lgr5-tdTomato;Stat $5^{f / f}$ or icS5) to determine the effect of inducible hyperactivation of icS5 or depletion of Stat5 on Lgr5 IESC progenies (Hameyer et al, 2007). Rosa26 ${ }^{\mathrm{mT} / m G}$ mice were crossed with Lgr5CreER;icS5 mice to determine the effects of icS5 upon Lgr5 IESC differentiation in organoids. The effects of inducible depletion of STAT5 upon Lgr5 ${ }^{+}$IESCS were investigated through crossing Stat $5^{f / f}$ mice with Lgr5CreER and VilCreER mice, by which Tam induction can efficiently deplete STAT5 in Lgr5 ${ }^{+}$IESCS (Kim et al, 2012). All mice used in these studies have been backcrossed with C57BL/ 6 for more than 10 generations and were re-genotyped with respect to floxed and Cre genes prior to necropsy. All studies were performed with littermate Stat $5^{f / f}$ or icS5 transgenic mice designated as WT controls, Stat5 $5^{f / f}$ mice with VilCre or VilCreER denoted as VilCre;Stat5 ${ }^{f / f}$ or VilCreER;Stat5 $5^{f / f}$ mice, and icS5 mice with Rs26creER or VilCreER mice denoted as Rs26CreER; icS5 or VilCreER;icS5 mice. All mice were maintained in specificpathogen-free conditions in the CHRF and ILAS Animal Care Facility. The animal study protocols were approved by the IACUC at CCHMC, Cincinnati, USA (IACUC2016-0100) and at ILAS, Beijing, P.R. China (HXN16001). Detailed procedures and genotyping for mouse crossing are described in Table S2 and Figs S2C, S3A, and S9A-C.

\section{C. difficile ileitis and colitis models}

Male or female mice aged 6-10 wk were treated with a cocktail of antibiotics $(0.4 \mathrm{mg} / \mathrm{ml}$ kanamycin, $0.035 \mathrm{mg} / \mathrm{ml}$ gentamicin, $850 \mathrm{U} / \mathrm{ml}$ colistin, $0.215 \mathrm{mg} / \mathrm{ml}$ metronidazole, and $0.045 \mathrm{mg} / \mathrm{ml}$ vancomycin) in drinking water for $5 \mathrm{~d}$. They were then removed from medicated water for $2 \mathrm{~d}$, at which time they received a single IP injection of clindamycin (30 mg/kg). The purpose of the antibiotic mixture in drinking water followed by the intraperitoneal injection (IP) of clindamycin was to alter the intestinal bacterial composition ("microbiome"). $2 \mathrm{~d}$ later, these mice were infected by oral gavage with $1-2.5 \times 10^{3}$ or $1 \times 10^{4}$ colony-forming units (CFU) of C. difficile spores diluted into $500 \mu \mathrm{l}$ of DMEM (strain NAP1, ATCC). From that time point forward, the mice were infectious and were housed in a BL2-compatible housing facility at CCHMC. From the time of infection, mice were examined and weighed twice daily for clinical symptoms and weight change. Mice were monitored twice daily during the acute stages of infection (until $96 \mathrm{~h}$ after inoculation). C. difficile infection is an acute disease, showing maximal symptoms and weight loss at 48-72 $\mathrm{h}$ after infection. We found that mice typically became symptomatic at $\sim 36 \mathrm{~h}$ and either succumbed or began to recover at 72-96 h after inoculation. Surviving mice were observed and weighed twice daily throughout the experiment and were either euthanized at predetermined time points (days 1-8) or were allowed to recover fully and were euthanized at days 10-21 after infection. At predefined experimental time points after infection, mice were euthanized by carbon dioxide inhalation (2 min) followed by cervical dislocation. The intestines, spleen, and mesenteric lymph nodes were then removed, rinsed in sterile PBS, then either were snap frozen in liquid nitrogen, fixed in PFA, or were placed in cold PBS. These samples were then taken back to our laboratory for RNA extraction, histopathology, or processing for flow cytometry, respectively. The analysis of the ileal and colonic disease severity is as follows: Lesion severity was graded with a system on a scale system as intestinal epithelial hyperplasia and damage (0-3), mucosal neutrophil margination and tissue infiltration (0-3), hemorrhagic congestion and edema of the mucosa (0-3), mucosal necrosis (0-3) (Chen et al, 2008; Hing et al, 2013). These procedures were approved to use in laboratories of Xiaonan Han (PI) IACUC (1E03030) and IBC (2012-0066) at CCHMC, Cincinnati and Xiaonan Han (PI) IACUC (HXN16001) at ILAS, Chinese Academy Institute of Medical Sciences (CAMS) \& Peking Union Medical College (PUMC), Beijing.

\section{Chronic DSS colitis model}

Mice were treated orally with three cycles of 7-d 3\% DSS with an interval of 5-d water recovery between each cycle of DSS (Fig S1C) (Wirtz et al, 2017). Mucosal histology was evaluated as a total score including intestinal epithelial damage (0-3), ulceration (0-3), and transmural lesion (0-3).

\section{Lineage-tracing in IECs, in enteroids, or in transplanted HIOs}

Lgr5-tdTomato mice were crossed with icS5 floxed mice (hereafter called Lgr5-tdTomato;Stat5 or icS5), while Lgr5-LacZ mice were crossed with Stat5 floxed mice (hereafter called Lgr5-LacZ;Stat5) (Barker et al, 2007; Muzumdar et al, 2007; Barker \& Clevers, 2010). These compound mice allowed us to trace the effects of gain or loss of function of STAT5 in Lgr5 IESCS upon their progeny following Tam induction. After 1, 7, 15, 30, and $60 \mathrm{~d}$ following a single dose of Tam $(1 \mathrm{mg} / \mathrm{kg})$, ileums were isolated, immediately flushed with ice-cold PFA ( $4 \%$ formaldehyde, $0.2 \%$ glutaraldehyde, and $0.02 \%$ NP40 in PBS [which is deficient in $\mathrm{Mg}^{2+}$ and $\mathrm{Ca}^{2+}$ ]) and incubated for overnight in a 20 -fold volume of the same ice-cold PFA at $4^{\circ} \mathrm{C}$ on a rolling 
platform. The PFA was removed, and the fragments of jejunum, ileums, and colon were washed twice with cold PBS at room temperature on a rolling platform. Jejunal, ileal, or colonic tissues were rolled as "Swiss roll" and embedded with optimal cooling temperature compound (OCT) or paraffin. Tissue sections $(4 \mu \mathrm{M})$ were prepared and counterstained with DAPI. Red tdTomato ribbons and green GFP Lgr5 progeny were visualized under fluorescence microscope of Leica Live Cell. Lgr5 IESC lineages in the red ribbon were also determined with immunofluorescent staining. The numbers of ileal Paneth cells or colonic Paneth-like cells labeled by tdTomato were counted 14 or $60 \mathrm{~d}$ after a single dose of Tam. The PFA-fixed jejunal, ileal, or colonic tissues from Lgr5-RsLacZ;Stat5 mice were under $\beta$-galactosidase ( $\mathrm{LaCZ}$ ) according to a standard protocol. Tissue sections $(4 \mu \mathrm{M})$ were prepared and counterstained with HE. Blue LacZ ribbons were imaged under a Leica Live Cell (Fig S3).

Lgr5CreER-icS5 mice were crossed with Rosa ${ }^{m T / m G}$ mice. Lgr5Rosa ${ }^{m T / m G}$;icS5 mice were generated. Ileal enteroids were differentiated for $14 \mathrm{~d}$ and maintained in culture medium with $200 \mathrm{mM}$ $4 \mathrm{HT}$ for $4 \mathrm{~d}$. Red tdTomato color was imaged under Leica Live Cell inverted microscope prior to Cre-mediated recombination, whereas green GFP was recorded as video by Leica Live Cell $4 \mathrm{~d}$ after $4 \mathrm{HT}$ induction (Fig 3D). Lgr5 IESC lineages were determined with immunofluorescent staining (Fig 3E).

LGR5:eGFP BAC reporter hESCs were transduced with lentiviral STAT5a-ER and icS5-ER mutants. HIOs were matured in vitro for $35 \mathrm{~d}$ and then were transplanted beneath the kidney capsule of immune-deficient NSG mice. After 2-mo engraftment, the transplanted mice were administered Tam at $25 \mathrm{mg} / \mathrm{kg}$ for 3 or 7 or 14 consecutive days. LGR5 lineages in the transplanted HIOs were traced with GFP fluorescent staining (Fig 6G).

\section{Ileal and colonic crypt isolation, enteroid and colonoids differentiation, and treatments with irradiation, inflammatory cytokines, or bacterial toxins}

Ileal or colonic crypts were isolated from Lgr5CreER;VilCreER;Stat5 $5^{f / f}$ or icS5 and Lgr5-Rosa26 ${ }^{\mathrm{mT} / m G}$;icS5 mice by manually shaking, then were dissociated with chelation buffer (1 mM EDTA, 5 mM EGTA, 0.5 mM DTT, 43.3 mM sucrose, and 54.9 mM sorbitol) (Sato et al, 2009; Gilbert et al, 2015). After filtered by $70-\mu \mathrm{m}$ cell strainer, over 200 ileal crypts were re-suspended in Matrigel with $50 \mathrm{ng} / \mathrm{ml}$ EGF, $100 \mathrm{ng} / \mathrm{ml}$ noggin, and $500 \mathrm{ng} / \mathrm{ml}$ R-spondin, or over 200 colonic crypts were re-suspended in Matrigel with EGF, noggin, and R-spondin, $100 \mathrm{ng} / \mathrm{ml}$ Wnt3a, and $10 \mu \mathrm{M}$ Y27432. Enteroids or colonoids were differentiated in the four-well culture plates from days 1 to 14 as published and then frozen in liquid nitrogen (Gilbert et al, 2015). Before any experiments, enteroids or colonoids were recovered and passaged at least two generations. 4HT (200 nM) was used to induce icS5 activation in enteroids after 4-d maturation. Enteroids or colonoids were then exposed to 4 Gy radiation for 10 min on day 4 (Fig 4D and G), or TNF $\alpha$, toxin $\mathrm{A}$, or toxin $\mathrm{B}$ for $4 \mathrm{~d}$ on day 4 in the presence or absence of $4 \mathrm{HT}$, to study the effects of icS5 upon irradiation injury, inflammatory cytokines, or bacterial toxins (Fig 5A). Lgr5 IESC self-renewal or proliferation was imaged and quantified as the number of buds $\left(\mathrm{org}^{3+}, \mathrm{org}^{2}, \mathrm{org}^{1}\right.$, and Sphere) and size of spheres. Viability of enteroids or colonoids was determined by Methylene Blue staining (Figs $5 \mathrm{C}$ and S5C). Enteroid or colonoid growth was video-recorded with a Live Image System
(Leica Live Cell, Leica). Lgr5-GFP buds were counted in each well, and the number of buds produced by an individual enteroid or coronoids per day was expressed as budding curves. Organoid-forming capacity in the presence or absence of TNF- $\alpha$ was determined by counting final organoid survival and initial-grown organoids to calculate the percentage of regenerated organoids. Six-replicate wells for each mouse were assessed for each experiment (Fig S5C) (Nakanishi et al, 2016; Schewe et al, 2016).

\section{FACS}

The isolated crypts were dissociated to single-cell or doublet-cell with TrypLE express including 2,000 U/ml DNase (Sigma-Aldrich) for $30 \mathrm{~min}$ at $37^{\circ} \mathrm{C}$ while the enteroids were dissociated with TrypLE express for $15 \mathrm{~min}$ at $37^{\circ} \mathrm{C}$ (Yan et al, 2012; Gilbert et al, 2015; Sasaki et al, 2016). Dissociated IECS were passed through $20-\mu \mathrm{m}$ cell strainer (Celltrix) and washed with ice cold PBS. Viable IEC singlecells or doublets were gated by forward scatter, side scatter, and pulse-width parameter, and negative staining for 7-ADD (eBioscience) Fig S5A).

FACS analyses of Lgr5, pYSTAT5, Annexin V, CD24, and Ki67 and BrdU were performed by using isolated ileal crypt IECS or dissociated enteroids. IECs were extracted with 2 mM EDTA with manual shaking from crypts or were dissociated from enteroids with TrypLE express, followed by cell strainer filter to generate a single-cell or doublet suspension (Fig S5B). Singlet discrimination was sequentially performed using plots for forward scatter (FSC) (FSC-A versus FSC-H) and side scatter (SSC) (SSC-W versus SSC-H). Dead cells were excluded by scatter characteristics and 7-AAD staining. Lgr5 $5^{+}$IESCS were identified by their endogenous GFP expression. Populations with Lgr5 and CD24 co-staining were used to determine Lgr5:CD24 doublets along with immunofluorescence (IF). All FACS experiments were performed on an LSR II flow cytometer (BD Biosciences) at the CCHMC or BD FACSAria III cell (BD Bioscience) in the ILAS FACS Facility, and FACS data were analyzed using FlowJo software (Tree Star) (Gilbert et al, 2015).

\section{Single Lrg5 $5^{\text {hi }}$ intestinal stem cell sorting and "medium replacement" culture}

Lgr5 GFP hi GFPlow, and GFP' IESCs were sorted by BD FACSAria III cell. Single viable Lgr5 cells were gated by forward scatter, side scatter, and pulse-width parameter, and by negative staining for 7-AAD. The sorted cells were manually inspected by inverted microscopy (Fig S5B) (Sato et al, 2009; Yin et al, 2014). Up to 2,000 sorted ileal Lgr5GFP ${ }^{\text {hi }}$ IESCS were collected, pelleted, and embedded in Matrigel. Culture medium (Advanced DMEM/F12 supplemented with penicillin/streptomycin, $10 \mathrm{mM}$ Hepes, Glutamax, 1× N2, 1× B27 [all from Invitrogen] and $1 \mu \mathrm{M} \mathrm{N}$-acetylcysteine [Sigma-Aldrich] containing growth factors $50 \mathrm{ng} / \mathrm{ml}$ EGF, $100 \mathrm{ng} / \mathrm{ml}$ Noggin, $1 \mu \mathrm{g} / \mathrm{ml}$ R-spondin, and $100 \mathrm{mg} / \mathrm{ml}$ Wnt3a) was overlaid. Y-27632 (10 $\mu \mathrm{M})$ was added for the first $2 \mathrm{~d}$ to avoid anoikis. Growth factors and entire medium were replaced every $4 \mathrm{~d}$. Meanwhile, intact ileal crypts were dissociated with EDTA from the ileum of VilCreER or Rs26CreER;icS5 mice, and enetroids were differentiated from days 1 to 7 as above methods. The culture medium was collected every other day and transferred into the wells containing sorted Lgr5GFPhi IESCS. The 
numbers of viable enteroids were calculated in triplicate. Budding curves were created to monitor and compare the growth speed of sorted cell-derived enteroids with or without the transferred medium. For sorting/medium transfer culture experiments, at least three independent experiments were performed. For each experiment, crypts/cells were pooled from three ileums.

\section{Transduction of LGR5:eGFP H9 cells and generation of HIOs}

The generation of the LGR5:eGFP bacterial artificial chromosome (BAC) transgenic reporter $\mathrm{H} 9$ hESC line has been previously described (Watson et al, 2014). Briefly, the BAC RP11-59F15 was obtained from the Children's Hospital Oakland Research Institute (http://bacpac.chori.org/) and grown in SW10535 cells. A single colony was expanded in $\mathrm{LB}+\mathrm{cam}$ at $32^{\circ} \mathrm{C}$, and recombineering proteins were induced by incubation at $42^{\circ} \mathrm{C}$ for $20 \mathrm{~min}$. The recombination cassette consisted of eGFP-FRT-PGKgb2-neo/kan-FRT, 50-bp homology region in LGR5, and a 20-bp homology region to peGFP-PGKneo. The homology regions were selected to replace the initiator methionine of LGR5 with that of eGFP followed by a bovine growth hormone polyadenylation signal and FRT-flanked bifunctional kanamycin/G418 resistance cassette. The recombination cassette was electroporated into SW105 cells, and cells were selected on plates with cam and kanamycin (kan; $50 \mu \mathrm{g} / \mathrm{ml}$ ). Clones were analyzed for properly targeted LGR5 BAC by PCR and confirmed by sequencing and nucleofected into single-cell suspensions of H9 hESCs using the Amaxa Human Stem Cell Nucleofector Starter Kit. Cells were selected in G418 (200 ng/ml) for 2 wk. G418resistant cells were maintained in antibiotic indefinitely.

Production of lentiviral GFP, STAT5a-ER, and icS5-ER iPSCS and LGR5:eGFP was described as in the previously published study (Gilbert et al, 2015). Briefly, LGR5:eGFP or H9hESCs were digested to single cells with Accutase detachment solution (Cat. No. 00-4555-56; Thermo Fisher Scientific), washed and replated at $2 \times 10^{5}$ per well of a four well dish in mTeSR1 containing $10 \mu \mathrm{M}$ Y-27632 (Cat. No.

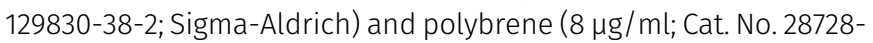
55-4; Sigma-Aldrich). Cells were then transduced by overnight incubation with lentivirus particles. Cells were then fed daily with fresh mTeSR1. Starting 3-d post-transduction, puromycin $(2 \mu \mathrm{g} / \mathrm{ml})$ was added to mTeSR1 to select for transduced cells. Upon reaching semi-confluence, cultures were passaged following the exposure to dispase $(1 \mathrm{mg} / \mathrm{ml}$ ) and gentle trituration to break cells into clumps, and replated in mTeSR1 + puromycin $(4 \mu \mathrm{g} / \mathrm{ml})$. Stably transduced hESC lines were then maintained in an undifferentiated state by daily feeding with fresh mTeSR1 + puromycin $(4 \mu \mathrm{g} / \mathrm{ml})$ and were expanded as colonies using standard dispase passaging methods.

For the generation of HIOs, LGR5:eGFP cells stably expressing Taminducible STAT5-ER or icS5-ER constructs and controls were transduced with lentivirus expressing eGFP and were differentiated as previously described (McCracken et al, 2011). Briefly, definitive endoderm was generated by exposure to recombinant human activin $\mathrm{A}$ for 3 d (100 ng/ml; Cat. No. 338-AC; R\&D Systems). Hindgut endoderm was generated by exposure to recombinant FGF4 (500 ng/ ml; Cat. No. 7460-F4-025; R\&D Systems) and CHIR99021 (3 M; Cat. No. 252917-06-9; StemCell Technologies) for $4 \mathrm{~d}$. Spontaneously derived spheroids were then embedded in matrigel (Cat. No. 354234; BD Biosciences) and incubated in media containing recombinant hEGF $(50 \mathrm{ng} / \mathrm{ml})$,
hNoggin $(100 \mathrm{ng} / \mathrm{ml})$, and hRSpondin1 (500 ng/ml), with complete media changes every $3 \mathrm{~d}$. HIOs were passaged and re-embedded in matrigel after $\sim 2$ wk in culture. Approximately $28 \mathrm{~d}$ after embedding, HIOs were harvested and used for in vitro permeability assay and transplanted into NSG mice as described in Watson et al, (2014).

\section{HIO microinjection, FITC-dextran (FD) 4 efflux, and epithelial integrity measurement by TEER}

Briefly, using a $7 \mathrm{nl} / \mathrm{sec}$ size microcapillary, each $\mathrm{HIO}$ was microinjected an $\sim 2.5 \mu \mathrm{l}$ mixture of $0.25 \mathrm{ng}$ of TNF $\alpha$ or $50 \mathrm{ng}$ of toxin B or $25 \mathrm{ng}$ of toxin A with $250 \mathrm{ng}$ of fluorescein isothiocyanate-dextran (FD, FD4) (Hill et al, 2017). Microinjection of HIOs. HIOs were gently removed from the Matrigel with a large opening-glass Pasteur glass pipette. Thin-wall glass capillaries (1B100F-4; World Precision Instruments) were pulled using a Sutter micropipette puller (P-97), and microinjection (PLI-100; Harvard Apparatus) was carried out in aseptic condition. FD4 was used in all microinjection experiments to aid in visualizing the injections. Once all of the HIOs were injected, the wells were washed twice with DMEM/F12 medium. The injected $\mathrm{HIOs}$ were incubated at $37^{\circ} \mathrm{C}$ in a $5 \% \mathrm{CO}_{2}$ humidified incubator. Then, the media were collected at a given time and the barrier integrity was measured by the signal intensity of FD4. Fluorescence was measured using a fluorescence spectrophotometer (Biotek Instruments) at an excitation wavelength of 492 and an emission wavelength of $515 \mathrm{~nm}$. Permeability was expressed as the mucosal-to-serosal clearance of FD4 (Han et al, 2010). 2-moold HIOs were excited open, and lumen intima was inverted. Intima was torn, and each $\mathrm{HIO}$ was dissected into three pieces around $1-2 \mathrm{~mm}^{2}$ area and mounted in Snapwell (P2307, area $=0.031 \mathrm{~cm}^{2}$ ) of EasyMount Ussing chamber systems (Physiological Instrument). TEER from individual piece of HIO was recorded 6, 12 and $24 \mathrm{~h}$ after microinjection of FD4, and the average of TEER of each HIO was manually calculated to represent individual $\mathrm{HIO}$ epithelial integrity.

\section{HIO kidney capsule transplantation}

H9 or LGR5:eGFP BAC reporter hESCs were transduced with lentiviral STAT5a-ER and icS5-ER mutants (Watson et al, 2014). HIOs were matured in vitro for $35 \mathrm{~d}$ and then were transplanted beneath the kidney capsule of immune-deficient NSG mice. Briefly, NSG mice were maintained by an antibiotic chow formula including Sulfamethoxazole (275 ppm, Test Diet) and Trimethoprim (1,365 ppm, Test Diet). Food and water were provided before and after surgeries. The matured HIOs were removed from matrigel, washed with cold phosphate-buffered saline (DPBS; Gibco), and embedded into purified type I collagen (rat tail collagen; BD Biosciences) $12 \mathrm{~h}$ before surgery to allow for the formation of a solidified gel plug. These plugs were then placed into standard growth media overnight in intestinal growth medium (Advanced DMEM/F-12, B27, $15 \mathrm{mM}$ Hepes, 2 mM l-glutamine, penicillin-streptomycin) supplemented with $100 \mathrm{ng} / \mathrm{ml}$ EGF (R\&D). HIOs were then transplanted under the kidney capsule. The mice were anesthetized with $2 \%$ inhaled isoflurane (Butler Schein), and the left side of the mouse was then prepped in sterile fashion with isopropyl alcohol and povidine-iodine. A small left-posterior subcostal incision was made to expose the kidney. A subcapsular pocket was created, and the 
collagen-embedded HIO was then placed into the pocket. The kidney was then returned to the peritoneal cavity, and the mice were given an IP flush of Zosyn (100 mg/ kg; Pfizer Inc.). The skin was closed in a double layer, and the mice were given a subcutaneous injection with Buprenex $(0.05 \mathrm{mg} / \mathrm{kg}$; Midwest Veterinary Supply) (Fig 6D). At 6-8 wk following the engraftment, the mice were then euthanized or subjected to lineage tracing or radiation experiment.

\section{Radiation-induced injury mouse models}

NSG mice with HIOs transplanted were induced by Tam $(1 \mathrm{mg} / \mathrm{kg})$ for $5 \mathrm{~d}$ and were exposed to $12 \mathrm{~Gy}$ whole body $\mathrm{\gamma}$-radiation for $10 \mathrm{~min}$ at Comprehensive Mouse and Cancer Core, CCHMC (Hua et al, 2012). The mice were intraperitoneally administered with BrdU 3.5-d postradiation and then euthanized $3 \mathrm{~h}$ later. The intestinal tissues were inspected for gross and histological abnormalities (Han et al, 2010; Hua et al, 2012). Radiation Injury Scores (RIS) and mucosal ulceration of radiation-induced intestinal mucositis were determined as previously described (Akpolat et al, 2009). RIS is a composite histopathologic scoring system that has been extensively improved by our laboratory. Briefly, the scores of $y$-radiation-induced ileal mucosal damages (scores: 1, 2, and 3), crypt loss (scores: 1, 2, and 3), mucosal ulcerations (scores: 1, 2, and 3), and thickening of intestinal wall (scores: 1, 2, and 3) were combined as RIS. The numbers of proliferating crypts or regenerated crypts ("microcolonies") were quantified as crypts per millimeter under microscope (magnification 100x) and were confirmed by BrdU labeling (Gilbert et al, 2015).

\section{RNA-seq}

Ileal or colonic crypts were isolated by shaking intestinal tissue in PBS with $10 \mathrm{mM}$ EDTA at $37^{\circ} \mathrm{C}$ for 30 min (Fig S8F). Total RNA was extracted using mirVana miRNA Isolation kit (Thermo Fisher Scientific) with total RNA extraction protocol. The RNA concentration was measured by NanoDrop (Thermo Fisher Scientific), and its integrity was determined by Bioanalyzer (Agilent). The RNA input was $1 \mu \mathrm{g}$ of RNA from each sample and they were pooled for CDNA library construction and sequencing on an Illumina HiSeq instrument with $1 \times 75$ bp reads at the Genomics, Epigenomics and Sequencing Core, Department of Environmental Health, University of Cincinnati. The BaseSpace (Illumina) applications TopHat Alignment (Version 1.0.0) and Cufflinks Assembly and Differential Expression (Version 1.1.0) were used to produce aligned reads and to perform novel transcript assembly and differential expression analysis. The Ingenuity Pathway Analysis tool from QIAGEN was used for pathway analysis and upstream regulator analysis of significant genes that showed more than twofold of differential expression. Finally, these co-regulated genes were subjected to the Distant Regulatory Elements (DiREs) server to predict common regulatory elements (Gotea \& Ovcharenko, 2008).

\section{Immunoblotting, immunohistochemistry, IF, whole-mount intestinal LacZ staining and quantitated real-time PCR (qRT-PCR)}

Isolated ileal IECS, HIOs, and mucosal tissue were saved. Total cellular protein (TP), cytosolic protein, and nuclear protein (NE) extracts were prepared using cold RIPA buffer and the NE-PER kit per the manufacturers' recommendations (Pierce). Expression of Lgr5, Bmi1, Dclk1, Lyso, and intercellular junctional proteins (ZO-1 or 2, Occludin, Claudin 1 and 2, E-Cadherin) in HIOs were measured in TP. The nuclear abundance of $\beta$-catenin and cleavage of the Notch intracellular domain protein (NICD), PYSTAT5, and STAT5a were detected in NE (Gilbert et al, 2012). Frozen tissues from mouse ileums and enteroids, and HIOs were prefixed in PFA. Sections $(4 \mu \mathrm{m})$ were labeled with pYSTAT5, ASCL2, BrdU, Ki67, Lyso, Muc2, E-Cadherin, CHGA, Lyso, ZO-1 or 3, Ki67 antibodies following FITC-conjugated or TRITC-conjugated anti-rabbit secondary antibodies, and DAPI was used for nuclear counterstaining. PYSTAT5 (phosphotyrosine), BrdU, and Ki67 were examined in paraffin-embedded intestinal sections using VECTASTAIN Elite ABC system (Vector lab). The full length of intestinal and colonic fragments were isolated from Tam-treated Lgr5-LacZ;Stat5 mice and immediately fixed with PFA LacZ solution. The fixed intestines were then stained with freshly made LacZ substrate overnight. Whole-mount intestinal analysis of in vivo lineage tracing was performed under 3D microscope (Zeiss). The images were scanned for overall measuring LacZ positive mucosa. Finally, the intestinal fragments were embedded and sectioned to analyze positive LacZ staining crypts under a microscope. Total RNA was extracted from mouse tissues or cultured enteroids using RNeasy Mini kit (QIAGEN) according to the manufacturer's protocol. PCRs were performed with SYBR Green qRT-PCR mix in the Mx3000p thermocycler (Stratagene) (Gilbert et al, 2012). The primer sequences (Zhang et al, 2015b; Gilbert et al, 2015; Nakanishi et al, 2016; Smith et al, 2017) are listed in Table S3.

\section{Statistics}

For all data analysis, the statistics software package SPSS (version 19.0) or GraphPad Prism (7.0) was used. Univariate survival analysis was subsequently carried out separately for each investigated parameter using Kaplan-Meier estimates. Survival curves were compared and assessed using the log-rank test. P-values of 0.05 or less were considered significant when using $t$ tests and ANOVA. RNA-seq data were analyzed by biostatisticians at University of Cincinnati and CCHMC, Cincinnati, OH, USA, University of Veterinary Medicine Vienna, Vienna, Austria, and ILAS, CAMS, and PUMC, Beijing, P.R. China.

\section{Transcript profiling}

GSE112607.

\section{Study approval}

The animal study protocols were approved by the IACUC at CCHMC, Cincinnati, USA (IACUC2016-0100), and at ILAS, CAMS, and PUMC, Beijing, P. R. China (HXN16001).

\section{Supplementary Information}

Supplementary Information is available at https://doi.org/10.26508/lsa. 201900296 


\section{Acknowledgements}

This work was supported by Crohn's Colitis Foundation of America Senior Research Award (426234, to X Han), NIAID R21 (Al103388 to X Han) and Cincinnati Children's Hospital Research Foundation Digestive Health Center (P30DK078392), NIH R01 (DK098231) (to L Denson), USA, and Peking Union Medical College Professor Scholar (2016RC310011 to X Han), P.R. China. $\mathrm{R}$ Moriggl was supported by a private cancer metabolism grant donation from Liechtenstein and the Austrian Science Fund (FWF), grants SFB F4707 and SFB-F06105, Austria.

\section{Author Contributions}

R Liu: data curation, formal analysis, and methodology.

R Moriggl: conceptualization, resources, formal analysis, investigation, and editing.

D Zhang: data curation and formal analysis.

H Li: data curation, formal analysis, and methodology.

R Karns: software and formal analysis.

H-B Ruan: formal analysis and methodology.

H Niu: data curation and methodology.

C Mayhew: data curation, methodology, and funding acquisition.

C Watson: data curation.

H Bangar: data curation.

S-w Cha: data curation and methodology.

D Haslam: conceptualization, formal analysis, and methodology.

T Zhang: software and formal analysis.

S Gilbert: data curation.

N Li: data curation.

M Helmrath: conceptualization, resources, and methodology.

J Wells: conceptualization, resources, methodology, investigation, and funding acquisition.

L Denson: conceptualization, formal analysis, methodology, and funding acquisition.

X Han: conceptualization, resources, formal analysis, data curation, supervision, funding acquisition, validation, investigation, visualization, methodology, project administration, writing-original draft, review, and editing.

\section{Conflict of Interest Statement}

The authors declare that they have no conflict of interest.

\section{References}

Abt MC, McKenney PT, Pamer EG (2016) Clostridium difficile colitis: Pathogenesis and host defence. Nat Rev Microbiol 14: 609-620. doi:10.1038/nrmicro.2016.108

Adolph TE, Tomczak MF, Niederreiter L, Ko HJ, Bock J, Martinez-Naves E, Glickman JN, Tschurtschenthaler M, Hartwig J, Hosomi S, et al (2013) Paneth cells as a site of origin for intestinal inflammation. Nature 503: 272-276. doi:10.1038/nature12599

Akpolat M, Kanter M, Uzal MC (2009) Protective effects of curcumin against gamma radiation-induced ileal mucosal damage. Arch Toxicol 83: 609-617. doi:10.1007/s00204-008-0352-4

Barker N (2014) Adult intestinal stem cells: Critical drivers of epithelial homeostasis and regeneration. Nat Rev Mol Cell Biol 15: 19-33. doi:10.1038/nrm3721
Barker N, Clevers H (2010) Lineage tracing in the intestinal epithelium. Curr Protoc Stem Cell Biol Chapter 5: Unit5A 4. doi:10.1002/9780470151808. sc05a04s13

Barker N, van Es JH, Kuipers J, Kujala P, van den Born M, Cozijnsen M, Haegebarth A, Korving J, Begthel H, Peters PJ, et al (2007) Identification of stem cells in small intestine and colon by marker gene Lgr5. Nature 449: 1003-1007. doi:10.1038/nature06196

Basak O, Beumer J, Wiebrands K, Seno H, van Oudenaarden A, Clevers H (2016) Induced quiescence of Lgr5+ stem cells in intestinal organoids enables differentiation of hormone-producing enteroendocrine cells. Cell Stem Cell 20: 177-190.e4. doi:10.1016/j.stem.2016.11.001

Basak O, van de Born M, Korving J, Beumer J, van der Elst S, van Es JH, Clevers H (2014) Mapping early fate determination in Lgr5+ crypt stem cells using a novel Ki67-RFP allele. EMBO / 33: 2057-2068. doi:10.15252/ embj.201488017

Berg AM, Kelly CP, Farraye FA (2013) Clostridium difficile infection in the inflammatory bowel disease patient. Inflamm Bowel Dis 19: 194-204. doi:10.1002/ibd.22964

Chen P, Tao L, Wang T, Zhang J, He A, Lam KH, Liu Z, He X, Perry K, Dong M, et al (2018) Structural basis for recognition of frizzled proteins by Clostridium difficile toxin B. Science 360: 664-669. doi:10.1126/science. aar1999

Chen X, Katchar K, Goldsmith JD, Nanthakumar N, Cheknis A, Gerding DN, Kelly CP (2008) A mouse model of Clostridium difficile-associated disease. Gastroenterology 135: 1984-1992. doi:10.1053/j.gastro.2008.09.002

Chen Y, Furuya-Kanamori L, Doi SA, Ananthakrishnan AN, Kirk M (2017) Clostridium difficile infection and risk of colectomy in patients with inflammatory bowel disease: A bias-adjusted meta-analysis. Inflamm Bowel Dis 23: 200-207. doi:10.1097/mib.0000000000000998

Chuang LS, Villaverde N, Hui KY, Mortha A, Rahman A, Levine AP, Haritunians T, Evelyn Ng SM, Zhang W, Hsu NY, et al (2016) A frameshift in CSF2RB predominant among Ashkenazi Jews increases risk for Crohn's disease and reduces monocyte signaling via GM-CSF. Gastroenterology 151: 710-723 e712. doi:10.1053/j.gastro.2016.06.045

el Marjou F, Janssen KP, Chang BH, Li M, Hindie V, Chan L, Louvard D, Chambon $P$, Metzger D, Robine S (2004) Tissue-specific and inducible Cremediated recombination in the gut epithelium. Genesis 39: 186-193. doi:10.1002/gene.20042

Farin HF, Karthaus WR, Kujala P, Rakhshandehroo M, Schwank G, Vries RG, Kalkhoven E, Nieuwenhuis EE, Clevers H (2014) Paneth cell extrusion and release of antimicrobial products is directly controlled by immune cell-derived IFN-gamma. J Exp Med 211: 1393-1405. doi:10.1084/jem.20130753

Ge Y, Fuchs E (2018) Stretching the limits: From homeostasis to stem cell plasticity in wound healing and cancer. Nat Rev Genet 19: 311-325. doi:10.1038/nrg.2018.9

Giesemann T, Guttenberg G, Aktories K (2008) Human alpha-defensins inhibit Clostridium difficile toxin B. Gastroenterology 134: 2049-2058. doi:10.1053/j.gastro.2008.03.008

Gilbert S, Nivarthi H, Mayhew CN, Lo YH, Noah TK, Vallance J, Rulicke T, Muller M, Jegga AG, Tang W et al (2015) Activated STAT5 confers resistance to intestinal injury by increasing intestinal stem cell proliferation and regeneration. Stem Cell Rep 4: 209-225. doi:10.1016/j. stemcr.2014.12.004

Gilbert S, Zhang R, Denson L, Moriggl R, Steinbrecher K, Shroyer N, Lin J, Han X (2012) Enterocyte STAT5 promotes mucosal wound healing via suppression of myosin light chain kinase-mediated loss of barrier function and inflammation. EMBO Mol Med 4: 109-124. doi:10.1002/ emmm.201100192

Gotea V, Ovcharenko I (2008) DiRE: Identifying distant regulatory elements of co-expressed genes. Nucleic Acids Res 36: W133-W139. doi:10.1093/ $\mathrm{nar} / \mathrm{gkn} 300$ 
Grebien F, Kerenyi MA, Kovacic B, Kolbe T, Becker V, Dolznig H, Pfeffer K, Klingmuller U, Muller M, Beug H, et al (2008) Stat5 activation enables erythropoiesis in the absence of EpoR and Jak2. Blood 111: 4511-4522. doi:10.1182/blood-2007-07-102848

Hameyer D, Loonstra A, Eshkind L, Schmitt S, Antunes C, Groen A, Bindels E, Jonkers J, Krimpenfort P, Meuwissen R, et al (2007) Toxicity of ligand-dependent $\mathrm{Cre}$ recombinases and generation of a conditional Cre deleter mouse allowing mosaic recombination in peripheral tissues. Physiol Genomics 31: 32-41. doi:10.1152/ physiolgenomics.00019.2007

Han X, Gilbert S, Groschwitz K, Hogan S, Jurickova I, Trapnell B, Samson C, Gully I (2010) Loss of GM-CSF signalling in non-haematopoietic cells increases NSAID ileal injury. Gut 59: 1066-1078. doi:10.1136/ gut.2009.203893

Heuberger J, Kosel F, Qi J, Grossmann KS, Rajewsky K, Birchmeier W (2014) Shp2/MAPK signaling controls goblet/paneth cell fate decisions in the intestine. Proc Natl Acad Sci USA 111: 3472-3477. doi:10.1073/ pnas.1309342111

Hill DR, Huang S, Tsai YH, Spence JR, Young VB (2017) Real-time measurement of epithelial barrier permeability in human intestinal organoids. J Vis Exp. doi:10.3791/56960

Hing TC, Ho S, Shih DQ, Ichikawa R, Cheng M, Chen J, Chen X, Law I, Najarian R, Kelly CP, et al (2013) The antimicrobial peptide cathelicidin modulates Clostridium difficile-associated colitis and toxin A-mediated enteritis in mice. Gut 62: 1295-1305. doi:10.1136/gutjnl-2012-302180

Hua G, Thin TH, Feldman R, Haimovitz-Friedman A, Clevers H, Fuks Z, Kolesnick R (2012) Crypt base columnar stem cells in small intestines of mice are radioresistant. Gastroenterology 143: 1266-1276. doi:10.1053/j.gastro.2012.07.106

Huang C, Haritunians T, Okou DT, Cutler DJ, Zwick ME, Taylor KD, Datta LW, Maranville JC, Liu Z, Ellis S, et al (2015) Characterization of genetic loci that affect susceptibility to inflammatory bowel diseases in African Americans. Gastroenterology 149: 1575-1586. doi:10.1053/j. gastro.2015.07.065

Johal SS, Solomon K, Dodson S, Borriello SP, Mahida YR (2004) Differential effects of varying concentrations of clostridium difficile toxin $A$ on epithelial barrier function and expression of cytokines. J Infect Dis 189: 2110-2119. doi:10.1086/386287

Kaplan GG (2015) The global burden of IBD: From 2015 to 2025. Nat Rev Gastroenterol Hepatol 12: 720-727. doi:10.1038/nrgastro.2015.150

Kaser A, Lee AH, Franke A, Glickman JN, Zeissig S, Tilg H, Nieuwenhuis EE, Higgins DE, Schreiber S, Glimcher LH, et al (2008) XBP1 links ER stress to intestinal inflammation and confers genetic risk for human inflammatory bowel disease. Cell 134: 743-756. doi:10.1016/j. cell.2008.07.021

Kim TH, Escudero S, Shivdasani RA (2012) Intact function of Lgr5 receptorexpressing intestinal stem cells in the absence of Paneth cells. Proc Natl Acad Sci USA 109: 3932-3937. doi:10.1073/pnas.1113890109

Leslie JL, Huang S, Opp JS, Nagy MS, Kobayashi M, Young VB, Spence JR (2015) Persistence and toxin production by Clostridium difficile within human intestinal organoids result in disruption of epithelial paracellular barrier function. Infect Immun 83: 138-145. doi:10.1128/ iai.02561-14

Li L, Clevers H (2010) Coexistence of quiescent and active adult stem cells in mammals. Science 327: 542-545. doi:10.1126/science.1180794

Martinelli M, Strisciuglio C, Veres G, Paerregaard A, Pavic AM, Aloi M, Martinde-Carpi J, Levine A, Turner D, Del Pezzo M, et al (2014) Clostridium difficile and pediatric inflammatory bowel disease: A prospective, comparative, multicenter, ESPGHAN study. Inflamm Bowel Dis 20: 2219-2225. doi:10.1097/mib.0000000000000219

McCracken KW, Howell JC, Wells JM, Spence JR (2011) Generating human intestinal tissue from pluripotent stem cells in vitro. Nat Protoc 6: 1920-1928. doi:10.1038/nprot.2011.410
Metcalfe C, Kljavin NM, Ybarra R, de Sauvage FJ (2014) Lgr5+ stem cells are indispensable for radiation-induced intestinal regeneration. Cell Stem Cell 14: 149-159. doi:10.1016/j.stem.2013.11.008

Monaghan TM, Cockayne A, Mahida YR (2015) Pathogenesis of Clostridium difficile infection and its potential role in inflammatory bowel disease. Inflamm Bowel Dis 21: 1957-1966. doi:10.1097/ mib.0000000000000461

Mori-Akiyama Y, van den Born M, van Es JH, Hamilton SR, Adams HP, Zhang J, Clevers H, de Crombrugghe B (2007) SOX9 is required for the differentiation of paneth cells in the intestinal epithelium. Gastroenterology 133: 539-546. doi:10.1053/j.gastro.2007.05.020

Moriggl R, Sexl V, Kenner L, Duntsch C, Stangl K, Gingras S, Hoffmeyer A, Bauer A, Piekorz R, Wang D, et al (2005) Stat5 tetramer formation is associated with leukemogenesis. Cancer Cell 7: 87-99. doi:10.1016/j. ccr.2004.12.010

Mowat AM, Agace WW (2014) Regional specialization within the intestinal immune system. Nat Rev Immunol 14: 667-685. doi:10.1038/nri3738

Muzumdar MD, Tasic B, Miyamichi K, Li L, Luo L (2007) A global doublefluorescent Cre reporter mouse. Genesis 45: 593-605. doi:10.1002/ dvg.20335

Nakai N, Ishikawa T, Nishitani A, Liu NN, Shincho M, Hao H, Isozaki K, Kanda T, Nishida T, Fujimoto J, et al (2008) A mouse model of a human multiple GIST family with KIT-Asp820Tyr mutation generated by a knock-in strategy. J Pathol 214: 302-311. doi:10.1002/ path.2296

Nakanishi Y, Reina-Campos M, Nakanishi N, Llado V, Elmen L, Peterson S, Campos A, De SK, Leitges M, Ikeuchi H, et al (2016) Control of Paneth cell fate, intestinal inflammation, and tumorigenesis by PKClambda/ iota. Cell Rep 16: 3297-3310. doi:10.1016/j.celrep.2016.08.054

Nam ST, Seok H, Kim DH, Nam HJ, Kang JK, Eom JH, Lee MB, Kim SK, Park MJ, Chang JS, et al (2012) Clostridium difficile toxin A inhibits erythropoietin receptor-mediated colonocyte focal adhesion through inactivation of Janus Kinase-2. J Microbiol Biotechnol 22: 1629-1635. doi:10.4014/jmb.1207.07063

Nusse YM, Savage AK, Marangoni P, Rosendahl-Huber AKM, Landman TA, de Sauvage FJ, Locksley RM, Klein OD (2018) Parasitic helminths induce fetal-like reversion in the intestinal stem cell niche. Nature 559: 109-113. doi:10.1038/s41586-018-0257-1

Rao K, Higgins PD (2016) Epidemiology, diagnosis, and management of Clostridium difficile infection in patients with inflammatory bowel disease. Inflamm Bowel Dis 22: 1744-1754. doi:10.1097/ mib.0000000000000793

Rothenberg ME, Nusse Y, Kalisky T, Lee JJ, Dalerba P, Scheeren F, Lobo N, Kulkarni S, Sim S, Qian D, et al (2012) Identification of a cKit(+) colonic crypt base secretory cell that supports Lgr5(+) stem cells in mice. Gastroenterology 142: 1195-1205 e1196. doi:10.1053/j. gastro.2012.02.006

Sangiorgi E, Capecchi MR (2008) Bmi1 is expressed in vivo in intestinal stem cells. Nat Genet 40: 915-920. doi:10.1038/ng.165

Sasaki N, Sachs N, Wiebrands K, Ellenbroek SI, Fumagalli A, Lyubimova A, Begthel H, van den Born M, van Es JH, Karthaus WR, et al (2016) Reg4+ deep crypt secretory cells function as epithelial niche for Lgr5+ stem cells in colon. Proc Natl Acad Sci USA 113: E5399-E5407. doi:10.1073/ pnas. 1607327113

Sato T, van Es JH, Snippert HJ, Stange DE, Vries RG, van den Born M, Barker N, Shroyer NF, van de Wetering M, Clevers H (2011) Paneth cells constitute the niche for Lgr5 stem cells in intestinal crypts. Nature 469: 415-418. doi:10.1038/nature09637

Sato T, Vries RG, Snippert HJ, van de Wetering M, Barker N, Stange DE, van Es JH, Abo A, Kujala P, Peters PJ, et al (2009) Single Lgr5 stem cells build crypt-villus structures in vitro without a mesenchymal niche. Nature 459: 262-265. doi:10.1038/nature07935

Schewe M, Franken PF, Sacchetti A, Schmitt M, Joosten R, Bottcher R, van Royen ME, Jeammet L, Payre C, Scott PM, et al (2016) Secreted 
phospholipases A2 are intestinal stem cell niche factors with distinct roles in homeostasis, inflammation, and cancer. Cell Stem Cell 19: 38-51. doi:10.1016/j.stem.2016.05.023

Schmitt M, Schewe M, Sacchetti A, Feijtel D, van de Geer WS, Teeuwssen M, Sleddens HF, Joosten R, van Royen ME, van de Werken HJG, et al (2018) Paneth cells respond to inflammation and contribute to tissue regeneration by acquiring stem-like features through SCF/ c-Kit signaling. Cell Rep 24: 2312-2328 e2317. doi:10.1016/j. celrep.2018.07.085

Sinagoga KL, Wells JM (2015) Generating human intestinal tissues from pluripotent stem cells to study development and disease. EMBO 34 : 1149-1163. doi:10.15252/embj.201490686

Smith NR, Davies PS, Levin TG, Gallagher AC, Keene DR, Sengupta SK, Wieghard N, El Rassi E, Wong MH (2017) Cell adhesion molecule CD166/ ALCAM functions within the crypt to orchestrate murine intestinal stem cell homeostasis. Cell Mol Gastroenterol Hepatol 3: 389-409. doi:10.1016/j.jcmgh.2016.12.010

Spence JR, Mayhew CN, Rankin SA, Kuhar MF, Vallance JE, Tolle K, Hoskins EE, Kalinichenko VV, Wells SI, Zorn AM, et al (2011) Directed differentiation of human pluripotent stem cells into intestinal tissue in vitro. Nature 470: 105-109. doi:10.1038/nature09691

Stark GR, Darnell JE Jr (2012) The JAK-STAT pathway at twenty. Immunity 36: 503-514. doi:10.1016/j.immuni.2012.03.013

Tan DW, Barker N (2014) Intestinal stem cells and their defining niche. Curr Top Dev Biol 107: 77-107. doi:10.1016/b978-0-12-416022-4.00003-2

van Es JH, Jay P, Gregorieff A, van Gijn ME, Jonkheer S, Hatzis P, Thiele A, van den Born M, Begthel $\mathrm{H}$, Brabletz T, et al (2005) Wnt signalling induces maturation of Paneth cells in intestinal crypts. Nat Cell Biol 7: 381-386. doi:10.1038/ncb1240

VanDussen KL, Liu TC, Li D, Towfic F, Modiano N, Winter R, Haritunians T, Taylor KD, Dhall D, Targan SR, et al (2014) Genetic variants synthesize to produce paneth cell phenotypes that define subtypes of Crohn's disease. Gastroenterology 146: 200-209. doi:10.1053/j. gastro.2013.09.048

Vijay-Kumar M, Aitken JD, Carvalho FA, Cullender TC, Mwangi S, Srinivasan S, Sitaraman SV, Knight R, Ley RE, Gewirtz AT (2010) Metabolic syndrome and altered gut microbiota in mice lacking Toll-like receptor 5. Science 328: 228-231. doi:10.1126/science.1179721

Watson CL, Mahe MM, Munera J, Howell JC, Sundaram N, Poling HM, Schweitzer Jl, Vallance JE, Mayhew CN, Sun Y, et al (2014) An in vivo model of human small intestine using pluripotent stem cells. Nat Med 20: 1310-1314. doi:10.1038/nm.3737

Watt FM, Huck WT (2013) Role of the extracellular matrix in regulating stem cell fate. Nat Rev Mol Cell Biol 14: 467-473. doi:10.1038/nrm3620

Wehkamp J, Wang G, Kubler I, Nuding S, Gregorieff A, Schnabel A, Kays RJ, Fellermann K, Burk O, Schwab M, et al (2007) The Paneth cell alphadefensin deficiency of ileal Crohn's disease is linked to Wnt/Tcf-4. J Immunol 179: 3109-3118. doi:10.4049/jimmunol.179.5.3109

Wierenga AT, Vellenga E, Schuringa JJ (2008) Maximal STAT5-induced proliferation and self-renewal at intermediate STAT5 activity levels. Mol Cell Biol 28: 6668-6680. doi:10.1128/mcb.01025-08
Wingelhofer B, Neubauer HA, Valent P, Han X, Constantinescu SN, Gunning PT, Muller M, Moriggl R (2018) Implications of STAT3 and STAT5 signaling on gene regulation and chromatin remodeling in hematopoietic cancer. Leukemia 32: 1713-1726. doi:10.1038/s41375-018-0117-x

Wirtz S, Popp V, Kindermann M, Gerlach K, Weigmann B, Fichtner-Feigl S, Neurath MF (2017) Chemically induced mouse models of acute and chronic intestinal inflammation. Nat Protoc 12: 1295-1309. doi:10.1038/ nprot.2017.044

Xu R, Nelson CM, Muschler JL, Veiseh M, Vonderhaar BK, Bissell MJ (2009) Sustained activation of STAT5 is essential for chromatin remodeling and maintenance of mammary-specific function. J Cell Biol 184: 57-66. doi:10.1083/jcb.200807021

Yan KS, Chia LA, Li X, Ootani A, Su J, Lee JY, Su N, Luo Y, Heilshorn SC, Amieva MR, et al (2012) The intestinal stem cell markers Bmi1 and Lgr5 identify two functionally distinct populations. Proc Natl Acad Sci USA 109: 466-471. doi:10.1073/pnas.1118857109

Yan KS, Gevaert O, Zheng GXY, Anchang B, Probert CS, Larkin KA, Davies PS, Cheng ZF, Kaddis JS, Han A, et al (2017) Intestinal enteroendocrine lineage cells possess homeostatic and injury-inducible stem cell activity. Cell Stem Cell 21: 78-90 e76. doi:10.1016/j.stem.2017.06.014

Yin X, Farin HF, van Es JH, Clevers H, Langer R, Karp JM (2014) Nicheindependent high-purity cultures of Lgr5+ intestinal stem cells and their progeny. Nat Methods 11: 106-112. doi:10.1038/nmeth.2737

Yoo KH, Oh S, Kang K, Hensel T, Robinson GW, Hennighausen L (2015) Loss of EZH2 results in precocious mammary gland development and activation of STAT5-dependent genes. Nucleic Acids Res 43: 8774-8789. doi:10.1093/nar/gkv776

Yu S, Tong K, Zhao Y, Balasubramanian I, Yap GS, Ferraris RP, Bonder EM, Verzi MP, Gao N (2018) Paneth cell multipotency induced by Notch activation following injury. Cell Stem Cell 23: 46-59.e5. doi:10.1016/j. stem.2018.05.002

Zhang Q, Pan Y, Yan R, Zeng B, Wang H, Zhang X, Li W, Wei H, Liu Z (2015a) Commensal bacteria direct selective cargo sorting to promote symbiosis. Nat Immunol 16: 918-926. doi:10.1038/ni.3233

Zhang R, Gilbert S, Yao X, Vallance J, Steinbrecher K, Moriggl R, Zhang D, Eluri M, Chen H, Cao H, et al (2015b) Natural compound methyl protodioscin protects against intestinal inflammation through modulation of intestinal immune responses. Pharmacol Res Perspect 3: e00118. doi:10.1002/prp2.118

Zhao F, Edwards R, Dizon D, Afrasiabi K, Mastroianni JR, Geyfman M, Ouellette AJ, Andersen B, Lipkin SM (2010) Disruption of Paneth and goblet cell homeostasis and increased endoplasmic reticulum stress in Agr2-/mice. Dev Biol 338: 270-279. doi:10.1016/j.ydbio.2009.12.008

Zhao M, Xiong X, Ren K, Xu B, Cheng M, Sahu C, Wu K, Nie Y, Huang Z, Blumberg RS, et al (2018) Deficiency in intestinal epithelial O-GlcNAcylation predisposes to gut inflammation. EMBO Mol Med 10: e8736. doi:10.15252/emmm.201708736

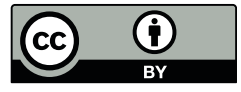

License: This article is available under a Creative Commons License (Attribution 4.0 International, as described at https://creativecommons.org/ licenses/by/4.0/). 